\title{
Neuronal Pentraxin 1 Contributes to the Neuronal Damage Evoked by Amyloid- $\beta$ and Is Overexpressed in Dystrophic Neurites in Alzheimer's Brain
}

\author{
Maria A. Abad, ${ }^{1}$ Marta Enguita, ${ }^{1}$ Nuria DeGregorio-Rocasolano, ${ }^{1}$ Isidre Ferrer, ${ }^{2}$ and Ramon Trullas ${ }^{1}$ \\ ${ }^{1}$ Neurobiology Unit, Institut d'Investigacions Biomèdiques de Barcelona, Consejo Superior de Investigaciones Científicas, Institut d'Investigacions \\ Biomèdiques August Pi i Sunyer, 08036 Barcelona, Spain, and 2Institut de Neuropatologia, Servei Anatomia Patològica, Hospital Universitari de Bellvitge, \\ Universitat de Barcelona, Hospitalet de Llobregat, 08097 Barcelona, Spain
}

\begin{abstract}
Accumulation of amyloid- $\beta(\mathrm{A} \beta)$ is thought to play a central role in the progressive loss of synapses, the neurite damage, and the neuronal death that are characteristic in brains affected by Alzheimer's disease. However, the mechanisms through which $A \beta$ produces such neurotoxicity remain unclear. Because $\mathrm{A} \beta$ depresses synaptic activity, we investigated whether the neurotoxicity of $\mathrm{A} \beta$ depends on the expression of NP1, a protein involved in excitatory synapse remodeling that has recently been shown to mediate neuronal death induced by reduction in neuronal activity in mature neurons. We found that treatment of cortical neurons in culture with $\mathrm{A} \beta$ produces a marked increase in NP1 protein that precedes apoptotic neurotoxicity. Silencing NP1 gene expression by RNA interference (short hairpin RNA for RNA interference) prevents the loss of synapses, the reduction in neurite outgrowth, and the apoptosis evoked by $A \beta$. Transgene overexpression of NP1 reproduced these neurotoxic effects of A $\beta$. Moreover, we found that NP1 was increased in dystrophic neurites of brains from patients with sporadic late-onset Alzheimer's disease. Dual immunohistochemistry for NP1 and tau showed that NP1 colocalizes with tau deposits in dystrophic neurites. Furthermore, NP1 colocalized with SNAP-25 (synaptosomal-associated protein of 25 $\mathrm{kDa}$ ) in the majority of dystrophic neurites surrounding amyloid deposits. NP1 was also increased in cell processes surrounding amyloid plaques in the cerebral cortex and hippocampus of APP/PS1 (mutant amyloid precursor protein/presenilin 1) transgenic mice. These findings show that NP1 is a key factor for the synapse loss, the neurite damage, and the apoptotic neuronal death evoked by A $\beta$ and indicate that $\mathrm{A} \beta$ contributes to the pathology of Alzheimer's disease by regulating NP1 expression.
\end{abstract}

Key words: neuronal pentraxin; programmed neuronal death; apoptosis; $\beta$-amyloid; neurite; neuropathology

\section{Introduction}

There is a pronounced loss of synapses in brain tissue from patients with Alzheimer's disease (AD), which is evident from the early stages of the disease (Davies et al., 1987; for review, see Selkoe, 2002). The loss of synapses and neurite damage are subsequently followed by the selective death of specific groups of neurons in the neocortex and limbic structures (Whitehouse et al., 1982). The loss of synapses strongly correlates with cognitive decline (DeKosky and Scheff, 1990). Accumulation of the amyloid- $\beta(\mathrm{A} \beta)$ peptide is one of the main characteristics of brains with $\mathrm{AD}$. Recent studies in mouse models of $\mathrm{AD}$ have shown that soluble $\mathrm{A} \beta$ oligomers interfere with synaptic function before structural synaptic damage and the ensuing neuronal

\footnotetext{
Received Feb. 8, 2006; revised 0ct. 25, 2006; accepted 0ct. 26, 2006.

This work was supported by the Ministerio de Sanidad y Consumo with Fondo de Investigaciones Sanitarias Grants PI02055 and PI040376 (R.T.) and PI040184 (I.F.), by Thematic Network for Cooperative Research Grant G03/167, by Ministerio de Educación y Ciencia Grant SAF2005-1167 (R.T.), and by "Fundació La Caixa” Project NE03/49-00.

Correspondence should be addressed to Dr. Ramon Trullas, Neurobiology Unit, Institut d'Investigacions Biomèdiques de Barcelona, Consejo Superior de Investigaciones Científicas, Institut d'Investigacions Biomèdiques August Pi i Sunyer, Rosselló 161, 08036 Barcelona, Spain. E-mail: rtonbi@iibb.csic.es.

D0I:10.1523/JNEUROSCI.0575-06.2006

Copyright $\odot 2006$ Society for Neuroscience $\quad$ 0270-6474/06/2612735-13\$15.00/0
}

death is induced (reviewed in (Walsh and Selkoe, 2004). Nonetheless, the detailed mechanism by which $\mathrm{A} \beta$ produces synaptic injury, leading to neurite degeneration and neuronal death, is still unknown.

The toxicity of $\mathrm{A} \beta$ in primary neuronal cultures displays morphological and biochemical characteristics of programmed cell death (Loo et al., 1993). Indeed, neuronal death evoked by $\mathrm{A} \beta$ in hippocampal cell cultures is prevented by inhibitors of protein and RNA synthesis (Takashima et al., 1993), indicating that A $\beta$ induces the expression of genes involved in the program of cell death. Moreover, the patterns of expression associated with this neuronal death program have been compared with those observed after the deprivation of trophic factors (Estus et al., 1997). Likewise, a reduction in neuronal activity triggers gene expression-dependent apoptosis in mature cerebellar granule neurons (D'mello et al., 1993), and, interestingly, it has been shown that $\mathrm{A} \beta$ selectively depresses excitatory synaptic transmission (Kamenetz et al., 2003). We therefore hypothesized that the neurotoxicity induced by $\mathrm{A} \beta$ might share a common mechanism with the apoptotic neurodegeneration induced by the reduction in neuronal activity.

We have reported previously that neuronal pentraxin 1 (NP1) is part of the apoptotic neuronal death program induced by the 
reduction in neuronal activity in mature cerebellar granule cells (DeGregorio-Rocasolano et al., 2001). NP1 is a member of the pentraxin family of proteins named for their distinct structural organization of five identical subunits arranged noncovalently in pentameric radial symmetry (Osmand et al., 1977). Neuronal pentraxins such as NP1 and NP2, also called activity-related pentraxin (Narp), and the neuronal pentraxin receptor (NPR) are selectively expressed in the nervous system and have been suggested to be involved in synaptic functions (Hsu and Perin, 1995; Schlimgen et al., 1995; Tsui et al., 1996; Dodds et al., 1997). NP1 and NP2/Narp are predicted to be secreted proteins, and NPR has been identified as a type II transmembrane protein with no intracellular domain (Dodds et al., 1997; O’Brien et al., 1999; Kirkpatrick et al., 2000). However, recent studies have shown that NPR has a number of different cytoplasmic isoforms that are often associated with the inner side of the plasma membrane, suggesting that neuronal pentraxins also have physiological functions as intracellular proteins (Chen and Bixby, 2005a,b). In our previous studies, we found that a reduction in neuronal activity induces the overexpression of NP1 and that this increase in NP1 protein leads to apoptotic neuronal death (DeGregorioRocasolano et al., 2001; Enguita et al., 2005). Based on the dual function of NP1 in synapse remodeling and apoptotic neurodegeneration, and because of the sequential association between the loss of synapses and delayed cell death in $\mathrm{AD}$, we asked whether NP1 might be implicated in the mechanisms underlying A $\beta$ neurotoxicity. Thus, we investigated the effect of oligomeric $\mathrm{A} \beta$ on NP1 expression in primary cortical cells in culture. Furthermore, we also studied the expression of NP1 in brains from patients diagnosed with $\mathrm{AD}$ as well as in brains from an animal model of $\mathrm{AD}$.

\section{Materials and Methods}

Cell culture. Primary cultures of brain cortical neurons were essentially prepared as described previously (Morishima et al., 2001). The frontallateral cortical lobes were dissected out of Sprague Dawley embryonic day 18 rat fetuses, and the cells were chemically dissociated in the presence of trypsin and DNase I before plating in poly-L-lysine $(100 \mu \mathrm{g} / \mathrm{ml})$ coated 24- or 6-well plates or on coverslips. For neuronal death assays, cortical cells were seeded at a density of $2 \times 10^{5}$ cells $/ \mathrm{cm}^{2}$ in basal Eagle's medium (BME) supplemented with 10\% fetal bovine serum (FBS; heat inactivated), $0.1 \mathrm{mg} / \mathrm{ml}$ gentamicin, $2 \mathrm{~mm}$ glutamine, $20 \mathrm{~mm}$ glucose, and $25 \mathrm{~mm} \mathrm{KCl}$. After $1 \mathrm{~d}$ in culture, the medium was changed to serum-free DMEM supplemented with B27 (Invitrogen, San Diego, CA), and the culture medium was partially replaced every $3 \mathrm{~d}$ with fresh DMEM supplemented with $\mathrm{B} 27$. Cortical cell cultures were kept at $37^{\circ} \mathrm{C}$ in a humidified incubator with $5 \% \mathrm{CO}_{2} / 95 \%$ air, and cortical neurons were used for experiments after 4-6 d in vitro (DIV). All procedures involving animals and their care were approved by the ethics committee of the University of Barcelona and were conducted in accordance with institutional guidelines in compliance with national (Generalitat de Catalunya) and international (Guide for the Care and Use of Laboratory Animals, National Academy Press, 1996) laws and policies.

Treatment of cortical cultures with A $\beta$ peptides. The A $\beta$ peptide (25$35)$, the inactive control $A \beta 35-25$, and $A \beta 1-42$ were purchased from Bachem (Bubendorf, Switzerland). One millimolar stock solutions of $A \beta 25-35$ and $A \beta 35-25$ were prepared in sterile water and stored at $-20^{\circ} \mathrm{C}$. A working solution of $0.5 \mathrm{~mm}$ was prepared in PBS for each peptide and directly diluted in the culture medium at the required concentration. Soluble oligomers of A $\beta 1-42$, were prepared as described previously (Lambert et al., 1998; Dahlgren et al., 2002; Klein, 2002).

Determination of cell viability and apoptosis in cortical cultures. Cell viability was assessed using two different methods. In some experiments, we used propidium iodide (PI) staining, which was excluded from viable cells. Damage to the cytoplasmic membrane permits the entry of PI, which yields a bright red fluorescence after its interaction with nuclear DNA. In time course experiments, PI fluorescence was measured in 24- well plates using a Cytofluor 2350 scanner (Millipore, Barcelona, Spain), with $530 \mathrm{~nm}$ ( $25 \mathrm{~nm}$ bandpass) excitation and $645 \mathrm{~nm}$ ( $40 \mathrm{~nm}$ bandpass) emission filters. The percentage of nonviable cells was measured using a modification of the method described by Rudolph et al. (1997) and DeGregorio-Rocasolano et al. (2001). In other experiments, the percentage of nonviable cells was measured by counting the number of PIstained and total cells using simultaneous fluorescence and phasecontrast photomicrographs obtained with an inverted Olympus (Tokyo, Japan) IX70 fluorescence microscope. In these experiments, cortical neurons were grown in 6-well plates, incubated with $5 \mu \mathrm{M}$ PI for $30 \mathrm{~min}$, fixed in $4 \%$ paraformaldehyde in PBS containing $2 \%$ sucrose for $30 \mathrm{~min}$ at room temperature, and rinsed with PBS before the addition of a final glycerol protective layer.

For morphological determination of apoptosis, cortical neurons were grown in 6-well plates, and the nuclei were stained with Hoechst 33258 (Sigma, St. Louis, MO). After removing the medium, the neurons were washed with ice-cold PBS, fixed with $4 \%$ paraformaldehyde in PBS containing $2 \%$ sucrose for $30 \mathrm{~min}$ at room temperature, and subsequently incubated with ice-cold methanol for $2 \mathrm{~min}$. The cells were then stained with Hoechst $33258(175 \mathrm{ng} / \mathrm{ml}$ in PBS) for $10 \mathrm{~min}$ at room temperature and covered with glycerol. Nuclei were visualized using an Olympus IX70 inverted fluorescence microscope with a $30 \times$ objective. In each experiment, photomicrographs were taken by a neutral observer from three randomly chosen fields per well, and at least three wells were examined for each treatment. Graphs based on cell counts represent the mean \pm SE from three independent experiments.

Determination of neurite outgrowth. Cortical neuronal cultures were seeded at $5 \times 10^{4}$ cells $/ \mathrm{cm}^{2}$ on Biocoat 6 -well plates coated with poly-Dlysine/mouse laminin (Becton Dickinson, Los Angeles, CA). Phasecontrast digital images were captured in live cortical neurons with an Olympus IX70 inverted fluorescence microscope with a $30 \times$ objective using the image analysis program AnalySIS (Soft Imaging System, Lakewood, CO). The length of neurites was determined using a stereological procedure (Ronn et al., 2000). The total neurite length per cell was estimated by counting the number of intersections made by neurites on 10 test lines in an unbiased counting frame superimposed on digital images of cell cultures. The absolute neurite length (L) was estimated per cell from the number of neurite intersections (I) per cell by applying the equation $\mathrm{L}=(\pi \mathrm{d} / 2)$ I to describe the relationship between the number of neurite intersections and the vertical distance $(\mathrm{d} ; 20 \mu \mathrm{m})$, between the 10 test lines used (Ronn et al., 2000).

Immunocytochemistry of primary cortical neuron cultures. Cortical neurons were plated in Permanox Lab-Tek Chamber slides (NalgeNunc) coated with poly-L-lysine $(100 \mu \mathrm{g} / \mathrm{ml})$ at a density of $5 \times 10^{4} \mathrm{cell} / \mathrm{cm}^{2}$ for neurite outgrowth and $2 \times 10^{5} \mathrm{cell} / \mathrm{cm}^{2}$ for cleaved caspase 3 immunocytochemistry. Neurons were fixed for 15 min with $4 \%$ paraformaldehyde in PBS containing $2 \%$ sucrose, permeabilized in $0.2 \%$ Triton X-100 for $5 \mathrm{~min}$ at room temperature, and rinsed in PBS. The coverslips were preincubated with blocking solution [10\% normal goat serum and $1 \%$ bovine serum albumin (BSA) in PBS] for $1 \mathrm{~h}$ and exposed to the primary antibodies diluted in $1 \% \mathrm{BSA} / \mathrm{PBS}$ overnight at $4^{\circ} \mathrm{C}$. The antibodies used were as follows: mouse anti- $\alpha$-tyrosinated-tubulin (1:800; Sigma); rabbit anti-human cleaved caspase-3 (1:100; Cell Signaling Technology, Beverly, MA); mouse anti-microtubule-associated protein 2 [MAP2 $(2 \mathrm{a}+$ 2b)] (1:250; Sigma); rabbit anti-synapsin 1 (1:500; Sigma); Alexa Fluor 568-conjugated $\mathrm{F}\left(\mathrm{ab}^{\prime}\right)_{2}$ goat anti-mouse IgG (1:1000; Invitrogen, Eugene, OR); Alexa Fluor 568-conjugated $\mathrm{F}\left(\mathrm{ab}^{\prime}\right)_{2}$ goat anti-rabbit IgG (1: 1000; Invitrogen).

Lentiviral vectors. The self-inactivating bicistronic lentiviral transfer vector constructs pWPI and pLVTHM, as well as the second-generation lentivirus packaging and envelope plasmids, were kindly provided by Dr. D. Trono (Lausanne, Switzerland) (Wiznerowicz and Trono, 2003, 2005; Zufferey et al., 1998). The pWPI lentiviral vector carries the EF1 $\alpha$ promoter and a $5^{\prime}$ to $3^{\prime}$ central polypurine tract, an expression cassette, the encephalomyocarditis virus internal ribosome entry site (IRES), and green fluorescent protein (GFP) encoded downstream of the IRES, as well as the post-transcriptional regulatory element of woodchuck hepatitis virus to enhance gene expression. In addition, the PLVTHM vector carries the H1 RNA polymerase III promoter to permit the expression of 
a short hairpin RNA for RNA interference (shRNAi) (Wiznerowicz and Trono, 2003). The map and the sequences of these plasmids are available at http://tronolab.epfl.ch/page58115.html. The coding sequence for NP1 was cloned from rat brain cDNA (Quick Clone cDNA; Invitrogen) by PCR. The pWPI-NP1-GFP vector was obtained by inserting the NP1 cDNA, containing the Kozak consensus sequence ACC before the initiation codon, by blunt end ligation into pWPI using the PmeI restriction sites. The vector pLVTHM-shRNAi-NP1-GFP was constructed to express short interfering RNAs to silence NP1 expression. A sequence targeting NP1 was selected based on the rules for RNAi susceptibility proposed by Tuschl's group (Elbashir et al., 2001) and using the RNAi prediction program from the Bioinformatics group of the Whitehead Institute for Biomedical Research. Two complementary DNA oligonucleotides (Roche, Berlin, Germany) were annealed to produce a doublestranded DNA fragment encoding a 19-nucleotide sense strand, 9-nucleotide loop, and 19-nucleotide antisense strand of the NP1 target or of a random sequence. The sequence of the NP1 shRNAi is as follows: 5' -gatccccGTACAGCCGCCTCAATTCT ttcaagagaAGAATTGAGGCGGCTGTACttttt-3' (sense) and 5'-agctaaaaaGTACAGCCGCCTCAATTCTtctcttgaaAGAATTGAGGCGGCTGTACggg-3' (antisense). The sequence in capitals is the NP1 target sequence that corresponds to bases 1004-1022 of the NP1 mRNA (GenBank accession number U18772). We also designed an shRNAi with a random sequence to use as a control lentivector. The sequence of the shRNAi-Random is as follows: 5'gatccccGCAGTGCAATATCGGAAACttcaagagaGTTTCCGATATTGCACTGCttttt-3' (sense) and 5'-agctaaaaaGCAGTGCAATATCGGAAACtctcttgaaGTTTCCGATATTGCACTGCggg - 3' (antisense). The duplex DNAs of shRNAi-NP1 and shRNAi-Random were cloned into the HindIII and BglII sites of the pSUPER.retro vector. After confirming the ability to silence NP1 in SH-SY5Y cells clones that permanently overexpress NP1, the H1-shRNA cassette was excised from pSUPER.retro and cloned into the lentiviral pLVTHM vector within EcoRI-ClaI sites.

The viral particles pseudotyped with vesicular stomatitis virus G glycoprotein were produced by transient transfection in 293T cells plated in $100 \mathrm{~mm}$ dishes in DMEM plus 10\% FBS. When subconfluent, 293T cells were cotransfected with $10 \mu \mathrm{g}$ of lentiviral vector containing the transgene, $7.5 \mu \mathrm{g}$ of the packaging plasmid psPAX2, and $3 \mu \mathrm{g}$ of the envelope plasmid pMD2G, using the FuGENE 6 transfection reagent (Roche). After $16 \mathrm{~h}$, the medium was changed, and the virus particles were harvested $24 \mathrm{~h}$ later by collecting the medium. High-titer stocks $\left(3 \times 10^{6}\right.$ transduction units per microliter) were obtained by ultracentrifugation and resuspension of the viral pellet in TNE buffer (50 mM Tris- $\mathrm{HCl}, \mathrm{pH}$ $7.5,130 \mathrm{~mm} \mathrm{NaCl}$, and $1 \mathrm{~mm}$ EDTA). Viral stocks were stored at $-20^{\circ} \mathrm{C}$ and used within 1 month.

Transduction of cortical neurons with lentiviral vectors. Lentivirus particles were added to cortical neuron cultures immediately after plating in a volume of $10-20 \mu \mathrm{l}$ of viral stock. After $24 \mathrm{~h}$ of incubation with the lentivirus, the medium was changed to serum-free DMEM supplemented with B27 (Invitrogen). The percentage of cortical neurons expressing GFP $48 \mathrm{~h}$ after lentiviral transduction was $80-90 \%$.

Oligodeoxyribonucleotide synthesis and treatment. A 21-base-long phosphorothioated antisense oligodeoxyribonucleotide (ODN) against the NP1 mRNA and its corresponding sense ODN were obtained from Roche Molecular Biochemicals (Pleasanton, CA). The sequences used were $5^{\prime}$-GCGTGCGGCGCGGCCGGCCAG-3' for the NP1 antisense ODN (NP1AS) and 5'-CTGGCCGGCCGCGCCGCACGC-3' for the corresponding sense ODN (NP1S). The phosphorothioated nucleotides are underlined. The NP1 antisense ODN sequence corresponds to nucleotides 4-24 that immediately follow the first initiation codon of the coding sequence of the NP1 cDNA. Silencing of NP1 expression in cortical neurons with ODNs was performed using LipofectAMINE 2000 reagent (Invitrogen). An NP1S or NP1AS $(0.8 \mu \mathrm{g})$ LipofectAMINE complex (1:3 ratio) was prepared according to the manufacturer's instructions and added to cortical neurons after 4 DIV. The culture medium conditioned by the cells was removed and saved. The cultures were washed with BME, and $0.4 \mathrm{ml}$ of transfection medium (BME without glutamine and antibiotics, at $37^{\circ} \mathrm{C}, \mathrm{pH} 7.4$ ) was added to the cultures. One hundred microliters of the DNA-LipofectAMINE complex mixture were added to each well, and the cells were incubated at $37^{\circ} \mathrm{C}$ in a $5 \% \mathrm{CO}_{2}$ incubator for $4 \mathrm{~h}$. The transfection medium was then removed by aspiration and replaced with conditioned medium. Experimental treatments with $\mathrm{A} \beta$ were initiated immediately afterward.

Protein expression and purification. The coding sequence for NP1 was subcloned into the BamHI and EcoRI restriction sites of the bacterial expression vector pGEX-4T-3 in frame with glutathione $S$-transferase (GST; Amersham Biosciences, Piscataway, NJ). The fusion protein expression construct pGEX-4T-3-GST-NP1 was transformed into Escherichia coli strain BL21 (DE3) pLys S (Novagen, Madison, WI), and fusion protein production was induced by the addition of isopropyl $\beta$-thiogalactoside to a final concentration of $0.4 \mathrm{~mm}$. After a $2 \mathrm{~h}$ induction at $37^{\circ} \mathrm{C}$, the cells were harvested. Because GST-NP1 was produced as inclusion bodies, pelleted cells were resuspended in inclusion body sonication buffer (25 mM HEPES, pH 7.7, $100 \mathrm{~mm} \mathrm{KCl,} 12.5 \mathrm{~mm} \mathrm{MgCl}_{2}, 20 \%$ glycerol, $0.1 \% \mathrm{v} / \mathrm{v}$ Nonidet P-40, $1 \mathrm{~mm}$ DTT, $1 \mathrm{~mm}$ PMSF, $2 \mu \mathrm{g} / \mathrm{ml}$ leupeptin, $2 \mu \mathrm{g} / \mathrm{ml}$ pepstatin, and $4 \mu \mathrm{g} / \mathrm{ml}$ aprotinin). In this, lysis was accomplished by a combination of lysozyme treatment (incubation with $0.5 \mathrm{mg} / \mathrm{ml}$ lysozyme for $30 \mathrm{~min}$ ), freeze-thaw cycles, and, finally, ultrasonication, and the lysate was then centrifuged at $8000 \times g$ for $10 \mathrm{~min}$ to pellet the inclusion bodies. Inclusion bodies were purified by washing twice with radioimmunoprecipitation assay buffer $(25 \mathrm{~mm}$ Tris- $\mathrm{HCl}, \mathrm{pH}$ 7.5, $150 \mathrm{~mm} \mathrm{NaCl}, 0.1 \%$ SDS, $1 \%$ Triton X-100, $1 \%$ sodium deoxycholate, and $1 \mathrm{~mm}$ PMSF) and solubilized in 2 vol of $10 \%$ SDS. Once the inclusion bodies were in solution, the concentration of SDS was adjusted to $1 \%$ by diluting the sample with PBS. To refold the denatured GSTNP1, the SDS concentration was further reduced to $0.01 \%$ by sequential dialysis. Finally, GST-NP1 was purified by glutathione-agarose affinity chromatography.

SDS-PAGE and Western blot analyses. Protein extracts were obtained from cell cultures at different times after treatment with $\mathrm{A} \beta$. The protein extracts of cultures exposed to lentiviral vectors were obtained $6 \mathrm{~d}$ after transduction. Cortical cells were solubilized in SDS sample buffer $(62.5$ mм Tris- $\mathrm{HCl}$, pH 6.8, 2\% SDS, 10\% glycerol, 2.5 mм EDTA, 75 mм DTT, and $0.01 \%$ bromophenol blue), and the homogenates were boiled for 5 min and briefly sonicated. The polypeptides were separated by $10 \%$ SDSPAGE and electroblotted onto polyvinylidene difluoride (PVDF) membranes (Millipore, Bedford, MA) according to the manufacturer's protocol. Blots were preincubated with $5 \%$ nonfat dry milk in Tris-buffered saline containing $0.1 \%$ Tween 20 before immunodetection. We used a monoclonal anti-rat NP1 antibody (1:1000; Becton Dickinson) for specific immunodetection of NP1 protein and a monoclonal antibody, clone SY 38 (1:1000; Chemicon, Ochsenhausen, Germany) for immunodetection of synaptophysin. Peroxidase-conjugated goat anti-mouse IgG (1: 10,000; Cell Signaling Technology) was used as the secondary antibody. To control for protein loaded, we used a rabbit anti-actin 20-33 antibody (1:3000; Sigma) and a peroxidase-conjugated goat anti-rabbit IgG (1: 5000; Cell Signaling Technology). Immunoreactive proteins were visualized using an enhanced chemiluminescence detection system (SuperSignal West Dura; Pierce, Rockford, IL), and the detection of the bands was performed using a VersaDoc Model 5000 Imaging System quantifying their intensity with the Quantity One computer software (Bio-Rad, Hercules, CA). The densitometric values of the bands representing NP1 or synaptophysin immunoreactivity were normalized to the values of the corresponding actin bands. The specificity of different NP1 antibodies was verified against recombinant NP1, NP2, and GFP proteins (supplemental Fig. 2, available at www.jneurosci.org as supplemental material).

Human brain samples. The brains of 10 patients with sporadic lateonset $\mathrm{AD}$ and 8 age-matched controls displaying no neurological illness were obtained at autopsy following the guidelines of the local Ethic Committee of the Hospital Universitari de Bellvitge, and after obtaining the informed consent from their relatives. The postmortem delay between death and tissue processing was between 3 and $6 \mathrm{~h}$ in control and diseased brains. Patients who had undergone prolonged agony were not included in this study. The AD patients were six men and four women with a mean age of 78 years, and the mean duration of the disease was 6.4 years. All of them died of natural causes at an advanced stage of the disease. Immediately after removal, coronal sections of the right cerebral and cerebellar hemispheres, and alternating 5-mm-thick sections of the brainstem, were frozen and stored at $-80^{\circ} \mathrm{C}$ for biochemical studies. In addition, 
5-mm-thick slices of the hippocampus and entorhinal cortex, as well as other brain regions, were immersed in $4 \%$ paraformaldehyde in phosphate buffer for $24 \mathrm{~h}$, washed in PBS, and embedded in paraffin for specific immunohistochemical studies.

The neuropathological study was performed on formalin-fixed, paraffin-embedded sections of the right cerebral hemisphere, cerebellum, and brainstem. The sections were stained with hematoxylin and eosin, cresyl violet, and Klüver Barrera, and they were processed for immunohistochemistry using the avidin-biotin-peroxidase method (ABC, Vectastain; Vector Laboratories, Burlingame, CA). Immunoreactivity of antibodies raised against the following was studied: phosphorylated neurofilament epitopes of 170 and $200 \mathrm{kDa}$ (clones BF10 and RT97, used at dilutions of 1:100 and 1:50, respectively), phosphorylated tau (mouse anti-AT8 antibody, diluted 1:50; Innogenetics, Gent, Belgium), monoclonal A $\beta$ (diluted 1:30; Sigma), and $\alpha$-synuclein (diluted 1:1000; Chemicon). In the case of the sections processed for $\mathrm{A} \beta$ and $\alpha$-synuclein staining, the tissue was pretreated with formic acid. Lewy bodies were not detected, and $\mathrm{AD}$ cases were categorized either as stages $\mathrm{V}$ and $\mathrm{VI}$ (neurofibrillary pathology) or as stage $\mathrm{C}$ ( $\mathrm{A} \beta$ deposition) of Braak and Braak (2001).

No tau pathologies were seen in control cases, and deposits of $\mathrm{A} \beta$ were restricted to a few diffuse plaques in the inferior region of the frontal lobe and the internal region of the temporal lobe in only one case [stage A of Braak and Braak (2001)].

Western blot studies. Western blot analysis of human brain tissue was performed on frozen samples of the hippocampus obtained from the same cases. Samples were homogenized in buffer containing $100 \mathrm{~mm}$ Tris, $\mathrm{pH} 7.4,150 \mathrm{~mm} \mathrm{NaCl}, 1 \%$ Triton $\mathrm{X}-100,1 \%$ sodium deoxycholate, $0.1 \%$ SDS, $5 \mathrm{~mm}$ EDTA, $1 \mathrm{~mm}$ phenylmethylsulfonyl fluoride, $5 \mathrm{mg} / \mathrm{ml}$ aprotinin, $5 \mathrm{mg} / \mathrm{ml}$ leupeptin, and $5 \mathrm{mg} / \mathrm{ml}$ pepstatin (Sigma). Equal amounts of protein (10 or $20 \mathrm{mg}$ ) were loaded in each lane with loading buffer containing $0.125 \mathrm{~mm}$ Tris, pH 6.8, 20\% glycerol, 10\% mercaptoethanol, $4 \%$ SDS, and $0.002 \%$ bromophenol blue. The samples were heated at $95^{\circ} \mathrm{C}$ for $10 \mathrm{~min}$ before gel loading. The proteins were separated by gel electrophoresis and transferred to nitrocellulose membranes (Amersham Biosciences) using an electrophoretic transfer system (TransBlot Semi-Dry Transfer Cell; Bio-Rad) at $40 \mathrm{~mA}$ for $1 \mathrm{~h}$. Subsequently, the membranes were blocked with Tris-buffered saline containing $0.05 \%$ Tween 20,5\% skimmed milk, 2\% BSA (Sigma), and 1\% normal serum (Vector Laboratories). Pilot experiments demonstrated that the polyclonal rabbit anti-NP1 antiserum (Becton Dickinson) but not the monoclonal anti-NP1 antibody recognizes human NP1. The membranes were incubated at $4^{\circ} \mathrm{C}$ overnight with anti-NP1 antibody (Becton Dickinson) used at a dilution of 1:200. After washing, the membranes were incubated with anti-rabbit IgG labeled with HRP (Dako, High Wycombe, UK) diluted 1:1000 for $1 \mathrm{~h}$ at room temperature. The membranes were washed again and developed with the chemiluminescence ECL system (Amersham Biosciences), followed by exposure of the membranes to autoradiographic films (Hyperfilm ECL; Amersham Biosciences). The protein content in each lane was evaluated by staining selected gels with Coomassie blue and membranes with Ponceau Red (Sigma). Selected membranes were immunostained with a mouse monoclonal antibody to $\beta$-actin to further control for protein loading. Control and AD cases were processed in parallel. The specificity of the polyclonal rabbit anti-NP1 antibody was confirmed by preabsorption of the antibody with the GST-NP1 recombinant protein.

NP1 single- and double-labeling immunohistochemistry. Sections were processed according to the avidin-biotin-peroxidase (ABC, Vectastain; Vector Laboratories) staining method. The sections were first boiled in citrate buffer and then stored overnight at room temperature. After blocking the endogenous peroxidase, the sections were incubated with normal serum and incubated at $4^{\circ} \mathrm{C}$ overnight with one of the primary antibodies. The polyclonal rabbit anti-NP1 antiserum was used at a dilution of 1:100. To test the specificity of the antibody, some sections were incubated with the rabbit anti-NP1 serum preabsorbed with the GSTNP1 recombinant protein. Other sections were incubated with only the secondary antibody. After incubation with the primary antibody, the sections were incubated for $1 \mathrm{~h}$ with biotinylated anti-rabbit IgG diluted $1: 100$, followed by $\mathrm{ABC}$ at a dilution of $1: 100$ for $1 \mathrm{~h}$ at room temperature.
The peroxidase reaction was visualized with $0.05 \%$ diaminobenzidine and $0.01 \%$ hydrogen peroxide (brown precipitate). Some sections were visualized with $\mathrm{NH}_{4} \mathrm{NiSO}_{4}(0.05 \mathrm{M})$ in phosphate buffer $(0.1 \mathrm{M})$, diaminobenzidine, $\mathrm{NH}_{4} \mathrm{Cl}$, and hydrogen peroxide (giving a dark blue precipitate). The tissue from control and diseased brains was processed in parallel to avoid day-to-day variations in the staining procedure. Other sections were stained with a mouse monoclonal antibody to synaptosomal-associated protein of $25 \mathrm{kDa}$ (SNAP-25; Abcam, Cambridge, UK) used at a dilution of 1:1000; the immunoreaction was visualized with $0.05 \%$ diaminobenzidine and $0.01 \%$ hydrogen peroxide. Sections were slightly counterstained with hematoxylin.

Dual immunohistochemistry was conducted following a two-step protocol in which the sections were first incubated with antibodies to $\mathrm{NP} 1$, and the immunoreaction was visualized with diaminobenzidine and hydrogen peroxide as above. Subsequently, the sections were incubated with AT8 antibody (Innogenetics) at a dilution of 1:50, and the immunocomplex was visualized with $0.01 \%$ benzidine hydrochloride, $0.025 \%$ sodium nitroferricyanide in $0.0001 \% \mathrm{~m}$ sodium phosphate buffer, $\mathrm{pH} 6.0$, and $0.005 \%$ hydrogen peroxide, or alternatively with $\mathrm{NH}_{4} \mathrm{NiSO}_{4}(0.05 \mathrm{M})$ in phosphate buffer $(0.1 \mathrm{M})$, diaminobenzidine, $\mathrm{NH}_{4} \mathrm{Cl}$, and hydrogen peroxide.

NP1 Immunofluorescence and confocal microscopy. Dewaxed hippocampal sections were stained with a saturated solution of Sudan black B (Merck, Darmstadt, Germany) for 30 min to block the autofluorescence of lipofuscin granules present in nerve cell bodies, rinsed in $70 \%$ ethanol, and washed in distilled water. The sections were incubated at $4^{\circ} \mathrm{C}$ overnight with anti-NP1 at a dilution of 1:100 and with monoclonal anti- $\mathrm{A} \beta$ at a dilution of 1:30 in a vehicle solution composed of Tris buffer, pH 7.2, containing $15 \mathrm{~mm} \mathrm{NaN}_{3}$ and protein (Dako). After washing in $\mathrm{PBS}$, the sections were incubated for $45 \mathrm{~min}$ at room temperature in the dark with the mixture of secondary antibodies diluted in the same vehicle solution as the primary antibodies. Other sections were incubated with anti-NP1 at a dilution of 1:100 and anti-SNAP-25 monoclonal antibody (Abcam) at a dilution of 1:1000. The secondary antibodies used were Alexa 488 anti-rabbit (green) and Alexa 546 (red) anti-mouse (both from Invitrogen), diluted 1:400. After washing in PBS, the sections were mounted in immuno-Fluore Mounting medium (ICN Biomedicals, Cleveland, $\mathrm{OH}$ ), sealed, and dried overnight. The sections were examined in a Leica (Nussloch, Germany) TCS-SL confocal microscope.

Mutant amyloid precursor protein/presenilin 1 transgenic mice. Mice were purchased from The Jackson Laboratory (Bar Harbor, ME). At the age of 12 months, the animals were perfused transcardially with saline, followed by $4 \%$ paraformaldehyde in phosphate buffer. The brain was separated from the skull and immersed in the same fixative solution for $24 \mathrm{~h}$. Coronal slabs were cryoprotected with $30 \%$ sucrose and frozen at $-80^{\circ} \mathrm{C}$. Cryostat sections $(10 \mu \mathrm{m})$ were obtained and processed free floating for immunohistochemistry following the $\mathrm{ABC}$ method as above, using antibodies against $\mathrm{A} \beta, \mathrm{NP} 1$, and anti-tau phospho-specific Thr ${ }^{181}$ (Calbiochem, La Jolla, CA) at a dilution of 1:250. The immunoreactivity was visualized with $\mathrm{NH}_{4} \mathrm{NiSO}_{4}(0.05 \mathrm{M})$ in phosphate buffer $(0.1 \mathrm{M})$, diaminobenzidine, $\mathrm{NH}_{4} \mathrm{Cl}$, and hydrogen peroxide. $\mathrm{A} \beta$ plaques were present in the cerebral cortex and hippocampus of transgenic mice but not in the corresponding age-matched littermates.

Statistical analysis. The results are expressed as the mean \pm SE of at least three separate experiments. The statistical significance of the differences was examined using independent $t$ tests or one-way ANOVA with Bonferroni post hoc multiple comparisons using the SPSS (Chicago, IL) statistical software package when required.

\section{Results}

$\mathrm{A} \boldsymbol{\beta}$ induces apoptotic neuronal death in cortical cultures

Previous studies in primary neuronal cultures have shown that the $A \beta 25-35$ peptide mimics the neurotoxic effects of the fulllength $\mathrm{A} \beta 1-42$ protein and induces the death of cortical neurons in a concentration-dependent manner (Yankner et al., 1990; Pike et al., 1995; Morishima et al., 2001). Thus, before studying the relationship between $\mathrm{A} \beta$ neurotoxicity and NP1 expression, we exposed primary cultures of rat cortical neurons to $30 \mu \mathrm{M} \mathrm{A} \beta 25-$ 
35 , a concentration that induces maximal cell death in this type of neuron (Morishima et al., 2001). Exposure of cortical cultures to the $\mathrm{A} \beta 25-35$ peptide $(30 \mu \mathrm{M})$ provoked a time-dependent increase in neuronal death as measured by the intensity of fluorescence after PI incorporation, the loss of neuronal viability evoked by A $\beta 25-35$ reaching $\sim 65 \%$ after a $48 \mathrm{~h}$ exposure. However, this neurotoxic effect of the $\mathrm{A} \beta 25-35$ peptide was not significant until after $18 \mathrm{~h}$ of treatment. In contrast, treatment with the reverse control peptide A $335-25$ did not produce any significant neurotoxicity, and control cultures exhibited $\sim 19 \%$ cell death after a $48 \mathrm{~h}$ exposure to the peptide (supplemental Fig. $1 A$, available at www.jneurosci.org as supplemental material).

Soluble oligomeric forms of synthetic $A \beta 1-42$ have been shown to kill Neuro-2A neuroblastoma cells and mature neurons in organotypic cultures of tissue from the CNS (Lambert et al., 1998; Dahlgren et al., 2002). Moreover, recent studies have shown that oligomerization of endogenous $A \beta$ is associated with neurite damage to cortical neurons and to the brain (Takahashi et al., 2004). We therefore studied the neurotoxicity of exogenous soluble oligomeric $A \beta 1-42$ in cortical neurons in culture.

Treatment of cortical cells with oligomeric $A \beta 1-42$ produced a time- and concentration-dependent reduction in neuronal viability (Fig. 1). The minimum effective concentration of $\mathrm{A} \beta 1-42$ that induced a significant increase in the percentage of apoptotic nuclei was $100 \mathrm{nM}(19 \% ; p=0.025)$, whereas the maximal neurotoxic effect was observed at a concentration of $10 \mu \mathrm{M}$ (Fig. $1 A$ ). The effect of this concentration of $\mathrm{A} \beta 1-42$ was time dependent and was not significant until the cells had been exposed to the peptide for $24 \mathrm{~h}$ (Fig. $1 \mathrm{~B}$ ). The effect of $\mathrm{A} \beta 1-42$ on neuronal death measured with PI staining was consistently higher than the effect on the percentage of apoptotic nuclei. For example, exposure of cultured cortical neurons to a $10 \mu \mathrm{M}$ concentration of $\mathrm{A} \beta 1-42$ for $48 \mathrm{~h}$ increased PI staining within a $50-65 \%$ range (Fig. $1 B$ ). In comparison, the same treatment produced a $35-$ $50 \%$ increase in the percentage of apoptotic nuclei (Fig. $1 A$ ). PI stains cells with damaged cytoplasmic membrane and provides an estimate of all cells that dye because of different processes (apoptosis as well as primary or secondary necrosis). In contrast, the percentage of condensed nuclei is a morphological assessment of cells that dye by apoptosis. The present results showing that $A \beta 1-42$ produces a higher increase in cell death than in apoptotic nuclei is consistent with previous studies showing that A $\beta 1-42$ may cause both apoptosis and necrosis in cultured neurons depending on the concentration and the time of exposure (Wei et al., 2002). Neuronal apoptosis usually requires the activation of caspase 3, produced by the proteolytic cleavage of its inactive zymogen into active fragments. To assess whether the apoptotic morphology induced by $\mathrm{A} \beta 1-42$ was associated with activation of caspase 3 , we performed immunocytochemistry studies using an antibody that recognizes only the active form of this enzyme. A $\beta 1-42(10 \mu \mathrm{M})$ induced a marked increase (control, $3 \pm 0.5 \%$ compared with $\mathrm{A} \beta, 15 \pm 3 \%$ ) in the percentage of cortical cells in which caspase 3 was cleaved $48 \mathrm{~h}$ after exposure to oligomeric A $\beta$ (Fig. $1 C$, bottom). Similarly, $52 \pm 2 \%$ of cortical neurons treated with $A \beta 1-42$ displayed pyknotic nuclei compared with $20 \pm 1 \%$ of neurons in control cultures (Fig. 1C, top).

$A \beta$ increases NP1 expression before inducing neuronal death Having defined the time course of $\mathrm{A} \beta$ neurotoxicity, we studied the accumulation of NP1 in cell extracts in the $24 \mathrm{~h}$ period before $\mathrm{A} \beta$ evokes significant membrane damage and neuronal death. The influence of either soluble $A \beta 1-42$ or $A \beta 25-35$ peptide on the accumulation of NP1 protein was studied as a function of the time of exposure. Treatment with $A \beta 25-35$ did not modify the expression of NP1 during the first $8 \mathrm{~h}$, but the levels of NP1 did increase $(327 \pm 48 \%$ the control values) after a $12 \mathrm{~h}$ exposure. This increase in the levels of NP1 protein induced by A $\beta 25-35$ was sustained for up to $18 \mathrm{~h}$ and decreased after $24 \mathrm{~h}$ of treatment. In contrast, the levels of actin protein did not significantly change after exposure to the $\mathrm{A} \beta$ peptide during the period studied (supplemental Fig. 1, available at www.jneurosci.org as supplemental material)

We next investigated the effect of $\mathrm{A} \beta$ oligomers on NP1 expression. Exposure to the oligomeric $A \beta 1-42$ produced a concentration-dependent increase in NP1 expression $(10 \mu \mathrm{M}$, $166 \pm 12 \% ; 20 \mu \mathrm{M}, 194 \pm 27 \%$ ), although this increase was not observed until $18 \mathrm{~h}$ after the exposure to the peptide (Fig. 2). Thus, compared with A $\beta 25-35$, the increase in NP1 accumulation after exposure to oligomeric $A \beta 1-42$ occurred later, and it was significantly lower at $24 \mathrm{~h}$ after the beginning of the treatment. Subsequent experiments showed that the effect of $20 \mu \mathrm{M}$ of A $\beta 1-42$ on NP1 expression was sustained and increased up to $458 \pm 77 \%$ over control at $60 \mathrm{~h}$ after the beginning of treatment. Although a marked increase in the accumulation of NP1 evoked by A $\beta 1-42$ was observed at $\sim 18 \mathrm{~h}$ after the beginning of the treatment (Fig. 2), the number of apoptotic nuclei does not appear to increase significantly until after 24 h of treatment with A $\beta$ (Fig. 1). Hence, these results indicate that $\mathrm{A} \beta$ increases NP1 protein levels before the appearance of morphological signs of apoptosis.

\section{Reduction in NP1 overexpression rescues cortical neurons from apoptosis evoked by $\mathrm{A} \boldsymbol{\beta}$}

To examine whether NP1 overexpression is necessary for the neurotoxic effects of $A \beta$, we adopted two different strategies to reduce NP1 expression. These involved the use of antisense ODNs and the lentivirus-mediated transduction of an shRNAi, both targeted against NP1 mRNA. In previous studies, we have shown that an antisense but not sense ODN (NP1AS not NP1S) significantly reduces NP1 protein levels in cells (DeGregorioRocasolano et al., 2001). Indeed, pretreatment of cortical neuronal cultures with NP1AS but not with the control ODN NP1S completely blocked the appearance of both apoptotic nuclei (Fig. $3 A$ ) and of cleaved caspase 3 (Fig. $3 B$ ) $48 \mathrm{~h}$ after treatment with oligomeric $A \beta 1-42$. This phenomenon was further confirmed when NP1 expression was silenced by RNAi. Lentivirus-mediated transduction of an shRNAi directed against NP1 transcripts significantly impaired the expression of NP1 protein evoked by oligomeric A $\beta 1-42$ (Fig. 3D). This effect appeared to be specific because an shRNAi expressing a random sequence did not affect the accumulation of NP1. Moreover, transduction of shRNAiNP1 but not of shRNAi-Random prevented the appearance of apoptotic nuclei $48 \mathrm{~h}$ after exposure of cortical neuronal cultures to oligomeric $\mathrm{A} \beta 1-42$ (Fig. $3 C$ ).

\section{NP1 mediates the reduction in neurite outgrowth evoked by $\mathrm{A} \boldsymbol{\beta}$}

Previous studies have shown that the neurite degeneration caused by $\mathrm{A} \beta$ in cultured neurons displays the morphological and biochemical characteristics of apoptosis (Ivins et al., 1998). Damage to neurites is one of the initial events in the process of neuronal death evoked by different apoptotic stimuli. Hence, because NP1 appears to mediate the apoptotic neuronal death induced by $\mathrm{A} \beta 1-42$, we investigated the role of NP1 in the neurite degeneration evoked by $A \beta$. In the first series of experiments, we studied the effect of $A \beta 1-42$ on neurite length by immunohistochemis- 

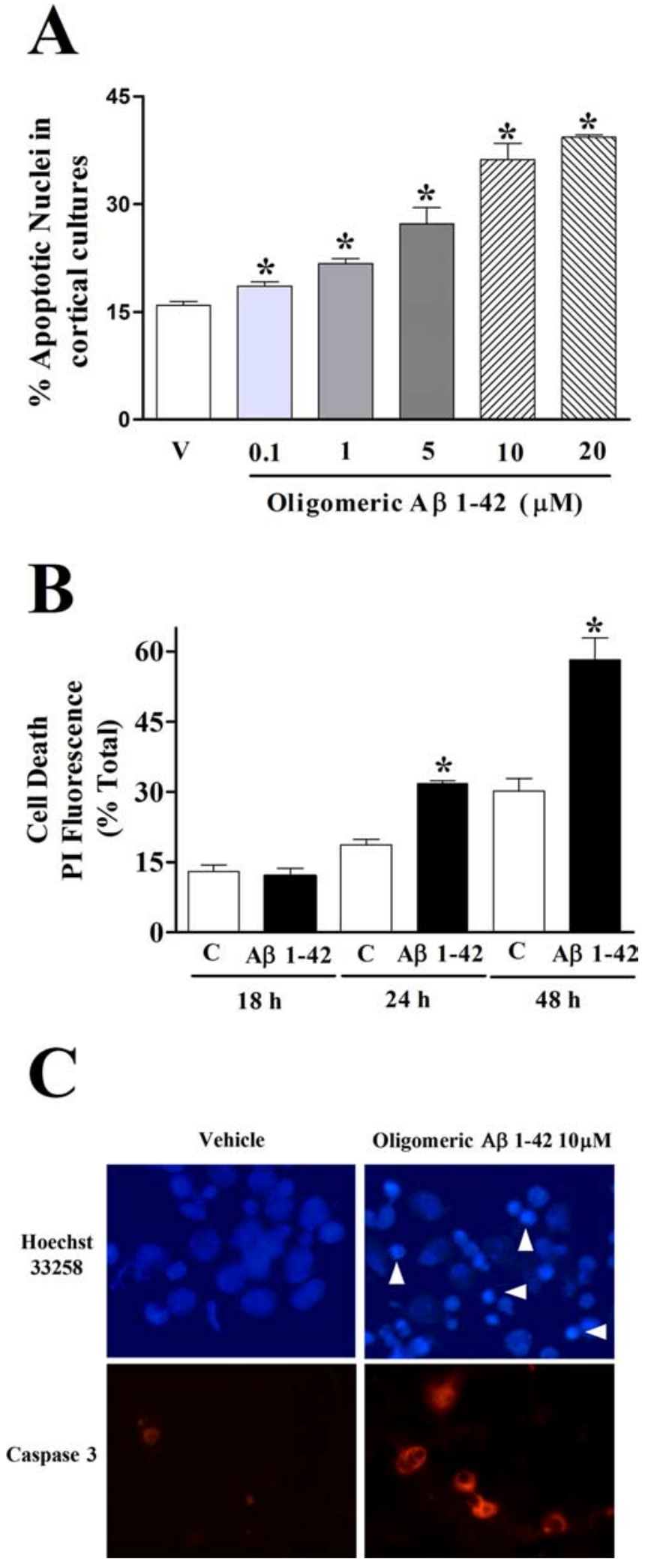

Figure 1. Oligomeric $A \beta 1-42$ induces apoptotic neuronal death. Cortical neuronal cultures (4-6 DIV) were treated with different concentrations of oligomeric $A \beta 1-42$. $A$, Soluble $A \beta 1-42$ increases the percentage of condensed nuclei in a concentration-dependent manner. Condensed nuclei were counted after Hoechst 33258 staining $48 \mathrm{~h}$ after treatment. V, Vehicle. $B$, Time course of neurotoxicity induced by soluble $A \beta 1-42(10 \mu \mathrm{m})$. In these experiments, neuronal death was measured by counting the number of PI stained over total number of cells in digital images of fluorescence and phase-contrast photomicrographs simultaneously obtained in an inverted fluorescence microscope. C, Control. C, Representative photomicrographs

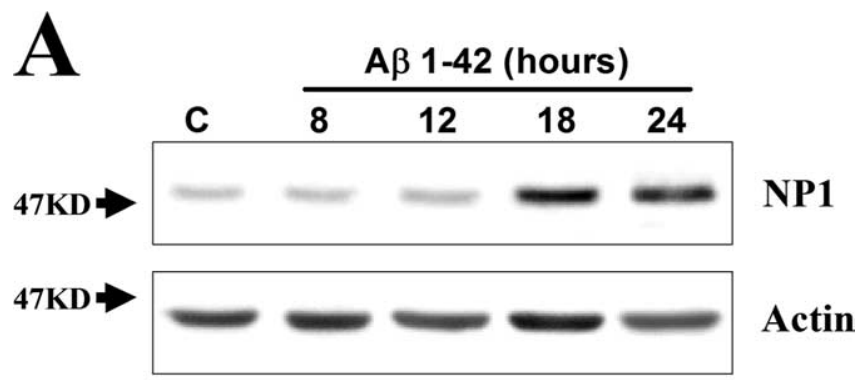

B

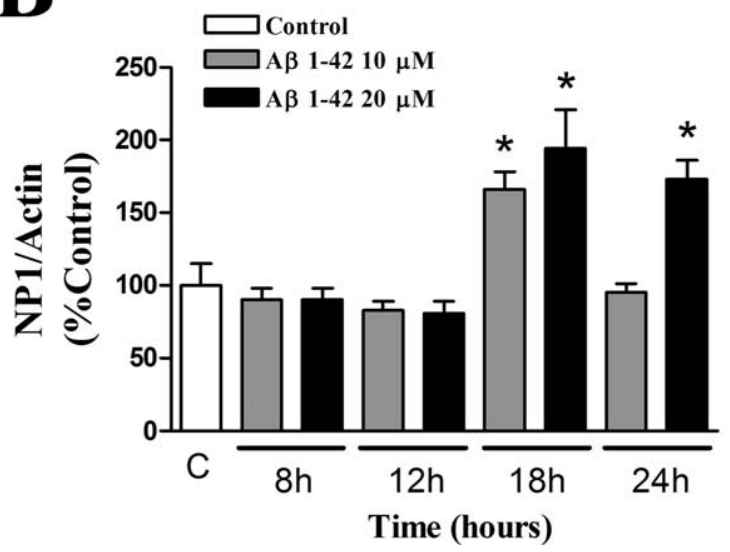

Figure 2. Oligomeric $A \beta 1-42$ increases NP1 expression in cortical neuronal cultures. $\boldsymbol{A}$, Representative Western blot showing the effect of a maximal concentration of oligomeric A $\beta 1-42(20 \mu \mathrm{M})$ on NP1 and actin levels over time. $B$, Quantitative analysis showing a concentration-dependent effect of oligomeric $A \beta 1-42(10$ and $20 \mu \mathrm{M})$ on NP1 protein levels. Western blots were incubated with mouse anti-NP1 antibody (1:1000). Densitometric values of the bands representing NP1 immunoreactivity were normalized with the values of the corresponding actin bands. The ratio of NP1 over actin was expressed as a percentage of the control values. Values are the mean \pm SEM of at least three independent experiments. ${ }^{*} p<0.05$, significantly different from control values (one-way ANOVA with Bonferroni post hoc comparisons). C, Control.

try of the tubulin network (Fig. 4A). Treatment of low-density cultures of cortical neurons with oligomeric $A \beta 1-42(10 \mu \mathrm{M})$ for $48 \mathrm{~h}$ produced a significant reduction $(30 \%)$ in the length of the neurites developed by the cells (control, $217 \pm 10 \mu \mathrm{m} ; \mathrm{A} \beta, 150 \pm$ $11 \mu \mathrm{m}$ ) (Fig. $4 B$ ). The reduction in neurite length evoked by A $\beta 1-42$ was antagonized by pretreatment with NP1AS but not with the control ODN NP1S (Fig. $4 B$ ). We also investigated the role of NP1 in the neurite damage induced by oligomeric $\mathrm{A} \beta 1-42$ by silencing NP1 expression using RNAi (Fig. $4 C$ ). When the neurite length in cortical neurons was measured in digital phasecontrast images, a $24 \mathrm{~h}$ exposure to $\mathrm{A} \beta 1-42(10 \mu \mathrm{M})$ produced a marked reduction (36\%) in the length of neurites developed by the cells (control, $215 \pm 12 \mu \mathrm{m} ; \mathrm{A} \beta, 137 \pm 9 \mu \mathrm{m}$ ) (Fig. $4 D$ ). In addition, this effect of soluble $A \beta 1-42$ on neurite length was impaired by the transduction of shRNAi-NP1 but not of shRNAiRandom (Fig. 4C,D). To determine whether this effect of $A \beta$ on

of cortical neuronal cultures treated with either vehicle or soluble $A \beta 1-42(10 \mu \mathrm{m})$ for $48 \mathrm{~h}$ and stained with Hoechst 33258 (top) or after immunocytochemistry for cleaved caspase 3 (bottom). Arrowheads indicate condensed nuclei. The data shown are from three independent experiments and are expressed as a percentage of the values in control cultures. ${ }^{*} p<0.05$, significantly different from the corresponding control (one-way ANOVA with Bonferroni post hoc comparisons). 
A

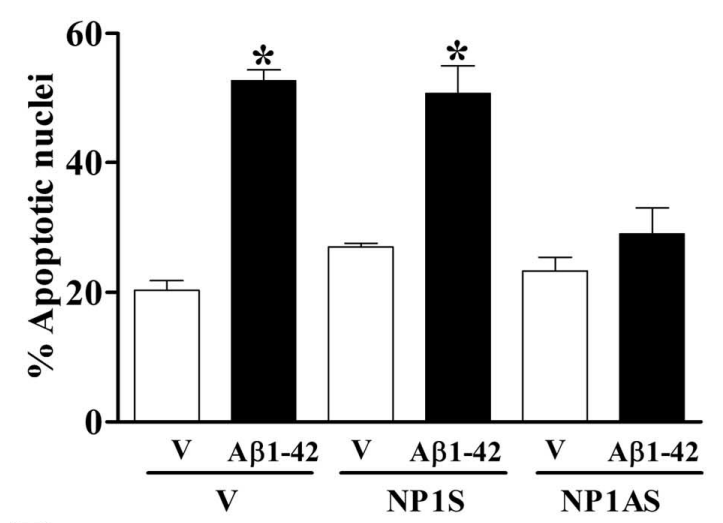

B

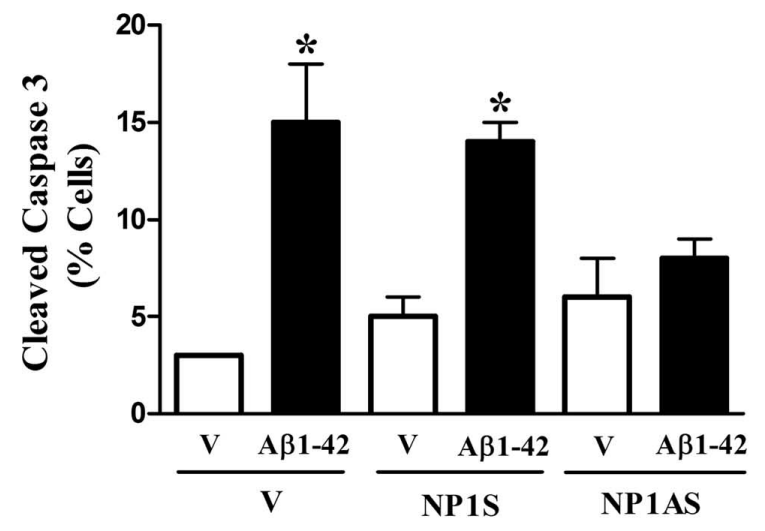

C

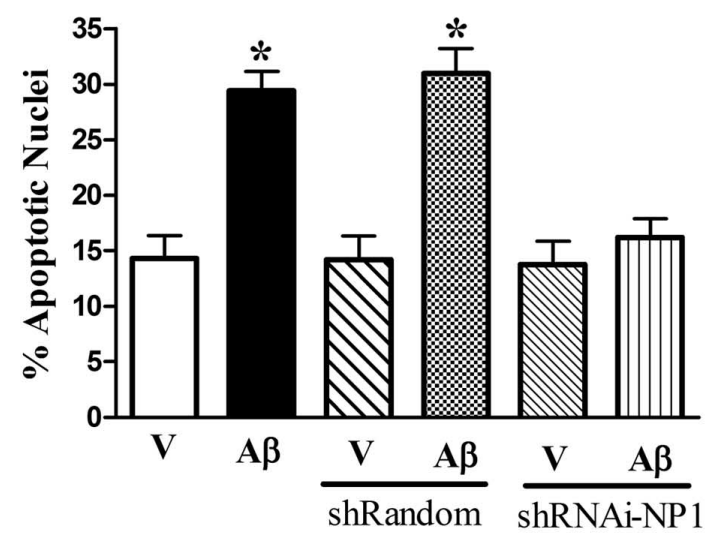

D

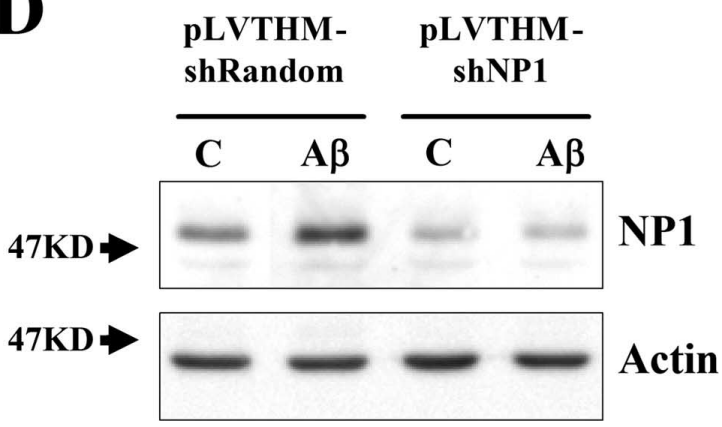

neurite length was also present in dendrites, we first examined the extent of differentiation of our neuronal cultures at 5 DIV. Double-immunofluorescence and confocal microscopy studies showed that MAP2 $(2 a+2 b)$ segregates in dendrites surrounded by synapsin 1 puncta, indicating that our cortical cultured neurons are polarized (supplemental Fig. 4, available at www. jneurosci.org as supplemental material). Subsequent studies showed that exposure to $\mathrm{A} \beta 1-42(10 \mu \mathrm{M})$ reduced the length of dendrites, and this effect was blocked by silencing NP1 expression with the transduction of shRNAi-NP1 (supplemental Fig. 3, available at www.jneurosci.org as supplemental material).

Silencing NP1 expression prevents synapse loss evoked by A $\beta$ Previous studies have shown that synapse loss occurs at early stages during progression of $\mathrm{AD}$ (Masliah et al., 2001). To analyze whether the reduction in neurite length evoked by $\mathrm{A} \beta$ is associated with synapse loss and to check whether this effect is also mediated by NP1 expression, we studied the effect of oligomeric $A \beta 1-42$ on the levels of the presynaptic vesicle protein synaptophysin. Treatment of cortical neuron cultures with oligomeric $\mathrm{A} \beta 1-42(20 \mu \mathrm{M})$ for $48 \mathrm{~h}$ produced a significant decrease $(\sim 60 \%)$ in the levels of synaptophysin. This effect was blocked by transduction of shRNAi-NP1, which silences NP1 expression, but not by transduction of the control hairpin shRNAi-Random (Fig. 5).

NP1 transgene overexpression reproduces the effects of $A \beta$ in terms of neurite damage and apoptosis

To determine whether NP1 alone is capable of reproducing the neurotoxic effects of $\mathrm{A} \beta 1-42$, we investigated the effect of lentivirus-mediated transgene overexpression of NP1 (Fig. 6). We treated cortical cells with the bicistronic lentiviral vectors pWPI-NP1, to induce the expression of a NP1 transgene and GFP, or with the control pWPI-GFP vector. The expression of GFP in cortical cells transduced with these vectors could be observed in $80-90 \%$ of neurons after $6 \mathrm{~d}$ treatment (data not shown). Likewise, there was a robust increase in NP1 protein levels after transduction with the pWPI-NP1 but not with the pWPI-GFP vector (Fig. 6A). This increase in NP1 protein was significantly diminished by RNAi of the NP1 message when pWPI-NP1 was cotransduced with the shRNAi-NP1 lentiviral vector. The increase in NP1 evoked by pWPI-NP1 was accompa-

\footnotetext{
$\leftarrow$

Figure 3. Silencing NP1 expression rescues cortical neurons from apoptosis evoked by $A \beta$. Expression of NP1 was silenced with antisense ODNs or with lentiviral-mediated RNAi. $\boldsymbol{A}, \boldsymbol{B}$, Cortical neuronal cultures were transfected with either antisense (NP1AS) or the corresponding sense (NP1S) ODN (0.8 $\mu \mathrm{g})$ at 4 DIV, as described in Materials and Methods. Approximately $4 \mathrm{~h}$ later, neurons were treated with vehicle or oligomeric $A \beta 1-42(10 \mu \mathrm{M})$. $A$, Apoptotic nuclei were measured with Hoechst 33258 staining $48 \mathrm{~h}$ after treatment with $A \beta$. $B$, The percentage of neurons with cleaved caspase 3 was measured by immunocytochemistry using a rabbit anti-human cleaved caspase-3 polyclonal antiserum $48 \mathrm{~h}$ after treatment with $10 \mu \mathrm{m} \mathrm{A} \beta 1-42$. C, Cortical neuronal cultures were transduced with a control lentivirus vector expressing a random sequence (pLVTHM-shRandom) or with a lentivirus vector expressing a short hairpin sequence that produces a small interfering RNA directed against NP1 mRNA (pLVTHM-shRNAiNP1). Ten to $20 \mu$ l of viral lentivirus particle stock were added at the same time of plating. The cells were treated with the vehicle or soluble $A \beta 1-42(10 \mu \mathrm{M})$ at 4 DIV, and apoptotic nuclei were measured with Hoechst 33258 staining $48 \mathrm{~h}$ after treatment with $A \beta$. D , Representative Western blot showing a reduction in NP1 protein levels after exposure to lentivirus-mediated RNAi. Proteins were extracted $18 \mathrm{~h}$ after treatment with $A \beta 1-42$, separated on $10 \%$ SDSPAGE, and transferred to PVDF membranes. Western blots were incubated with mouse anti-NP1 antibody (1:1000). ${ }^{*} p<0.05$, significantly different from control values (one-way ANOVA with Bonferroni post hoc comparisons). Values are mean $\pm \mathrm{SE}$ of three independent experiments. $\mathrm{V}$, Vehicle; C, control.
} 
A

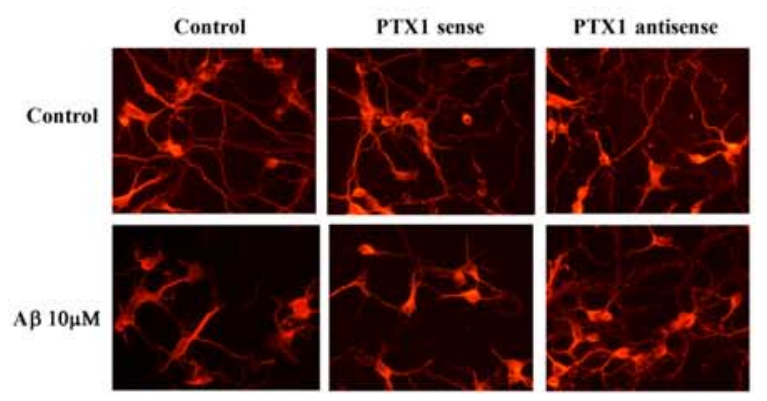

B
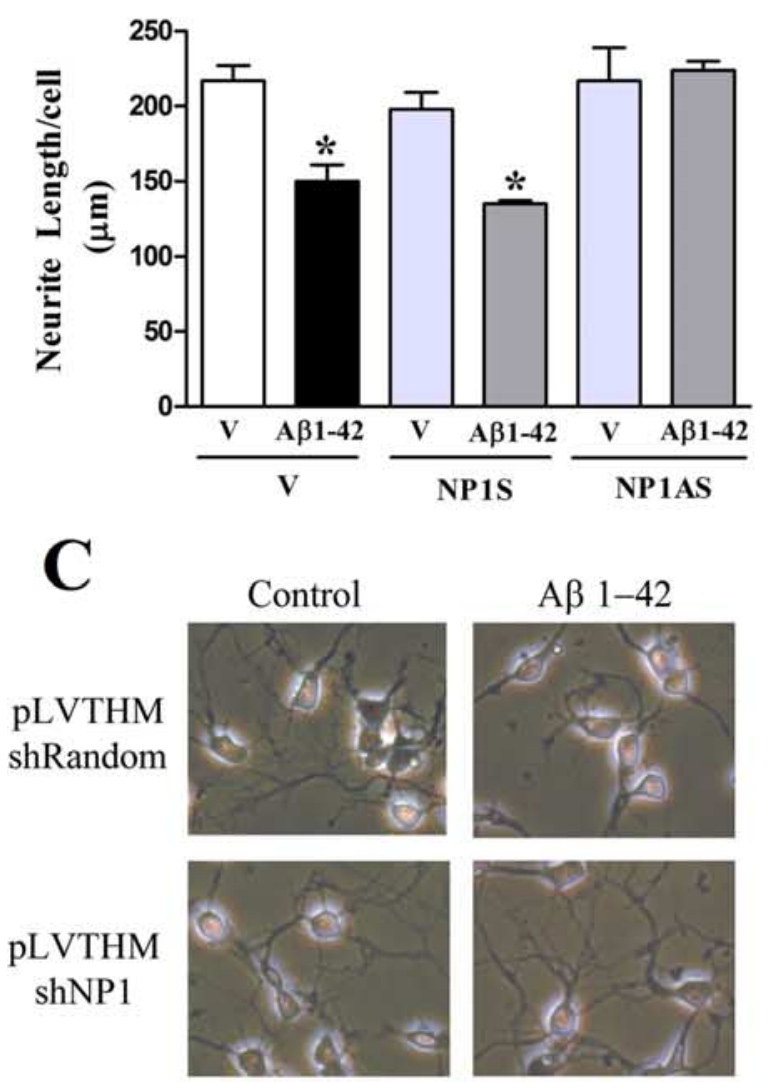

D

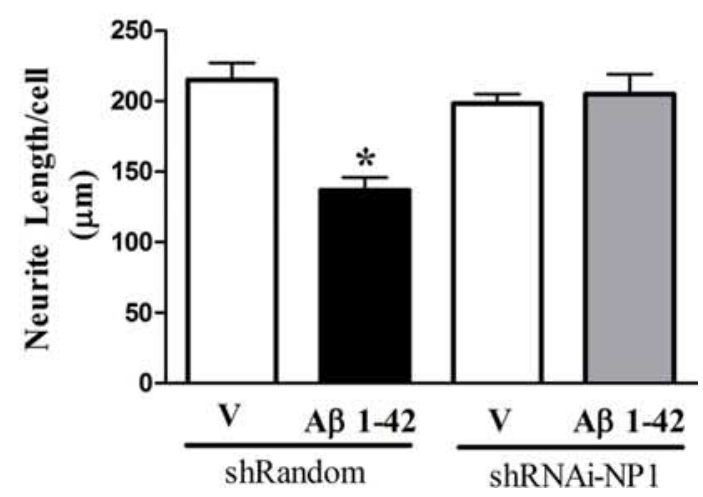

A
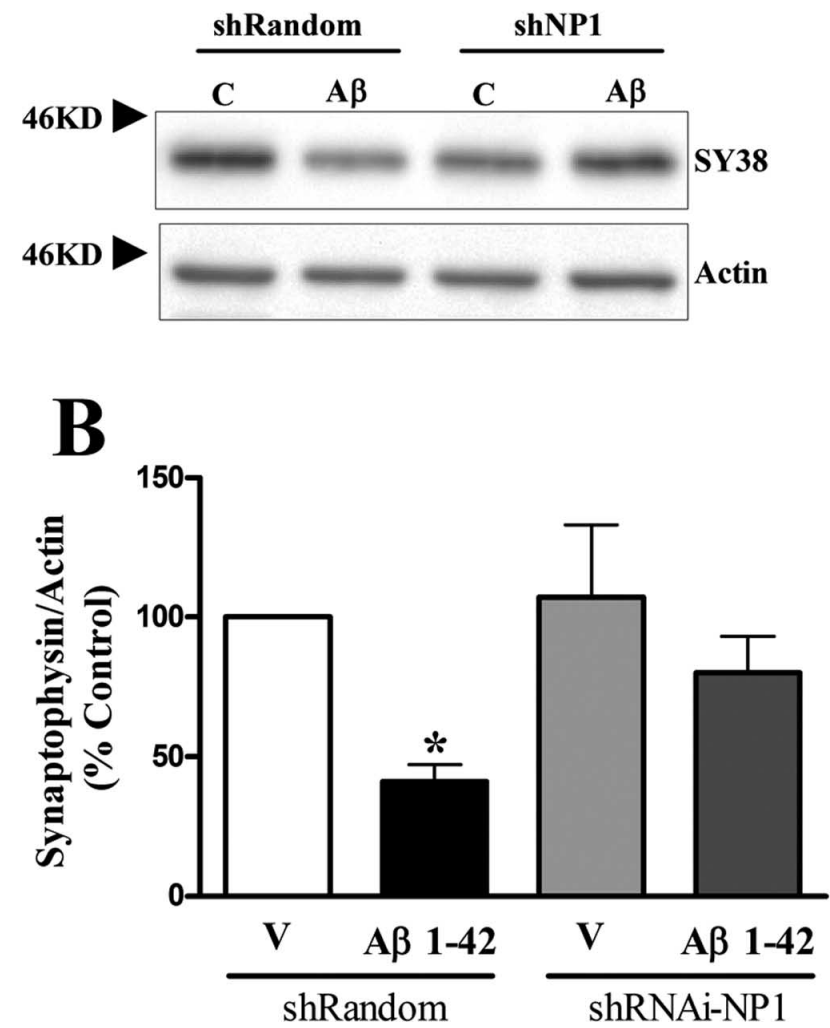

Figure 5. Silencing NP1 expression prevents synapse loss evoked by A 3 . Expression of NP1 was silenced with lentiviral-mediated RNAi. Cortical neuronal cultures were transduced with the control lentiviral vector pLVTHM-shRandom or with the lentiviral vector for RNAi against NP1, pLVTHMshRNAi-NP1. Five microliters of viral lentivirus particle stock were added at the same time of plating. The cells were treated with vehicle or oligomeric $A \beta 1-42(20 \mu \mathrm{m})$ at 5 DIV for $48 \mathrm{~h}$. $A$, Representative Western blot showing a reduction in synaptophysin protein levels after exposure to $A \beta$. Proteins were extracted $48 \mathrm{~h}$ after treatment with $A \beta 1-42$. Western blots were incubated with mouse antisynaptophysin antibody (SY38; 1:1000). Actin was used as control for protein loading. B, Quantitative analysis of the effects of $A \beta$ and NP1 RNAi on synaptophysin levels. The densitometric values of the bands representing synaptophysin immunoreactivity were normalized to the values of the corresponding actin band. Values are mean \pm SE of three independent experiments. ${ }^{*} p<0.05$, significantly different from control values (independent $t$ test). C, Control; V, Vehicle.

nied by a $33 \%$ reduction in the length of neurites in neurons $(210 \pm 11 \mu \mathrm{m}$ in neurons treated with the control vectors compared with $140 \pm 13 \mu \mathrm{m}$ in neurons overexpressing NP1) (Fig. $6 C$ ) and by a marked increase in the number of apoptotic nuclei

Figure 4. Silencing NP1 expression prevents the reduction in neurite outgrowth evoked by $A \beta$. Expression of NP1 was silenced with antisense ODNs or with lentiviral-mediated RNAi. $A, B$, Cortical neurons, plated at low density in Permanox coverslides, were transfected with either antisense (NP1AS) or the corresponding sense (NP1S) ODN $(0.8 \mu \mathrm{g})$ at 1 DIV. Approximately $4 \mathrm{~h}$ later, neurons were treated with vehicle or soluble $A \beta 1-42(10 \mu \mathrm{M})$ and fixed with $4 \%$ paraformaldehyde $48 \mathrm{~h}$ after treatment with $A \beta . A$, Representative immunofluorescence images of the tubulin network of cortical neuronal cultures assayed with anti- $\alpha$-tyrosinated-tubulin monoclonal antibody. $\boldsymbol{B}$, Total neurite length was estimated in photomicrographs of the tubulin network using a stereological procedure. $C$, Phase-contrast representative photomicrographs of cortical neurons transduced with a control lentivirus (pLVTHM-shRandom) or a lentivirus vector producing an NP1-specific small interfering RNA (pLVTHM-shRNAi-NP1). Lentivirus particles were added at the same time of plating, and treatment with vehicle or soluble $A \beta 1-42(10 \mu \mathrm{M})$ was performed at 1 DIV. D, Total neurite length was estimated from phase-contrast photomicrographs obtained from living cells $24 \mathrm{~h}$ after treatment with $A \beta$ using a stereological procedure (Ronn et al., 2000). Values are mean \pm SE of three independent experiments. ${ }^{*} p<0.05$, significantly different from control values (one-way ANOVA with Bonferroni posthoc comparisons). V, Vehicle. 

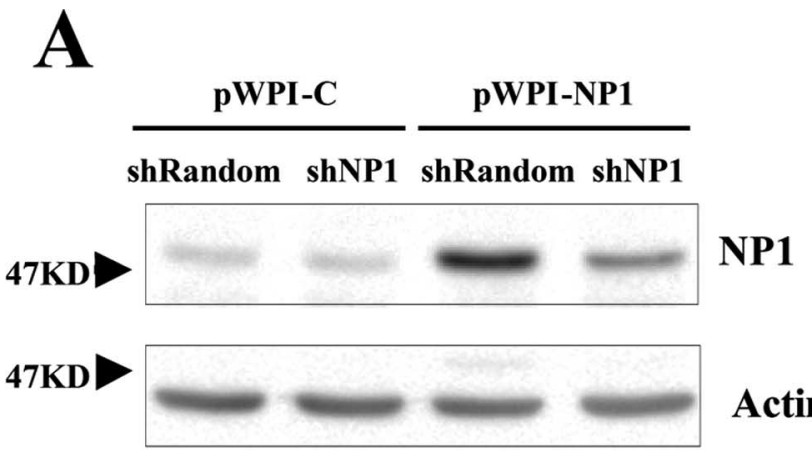

Actin
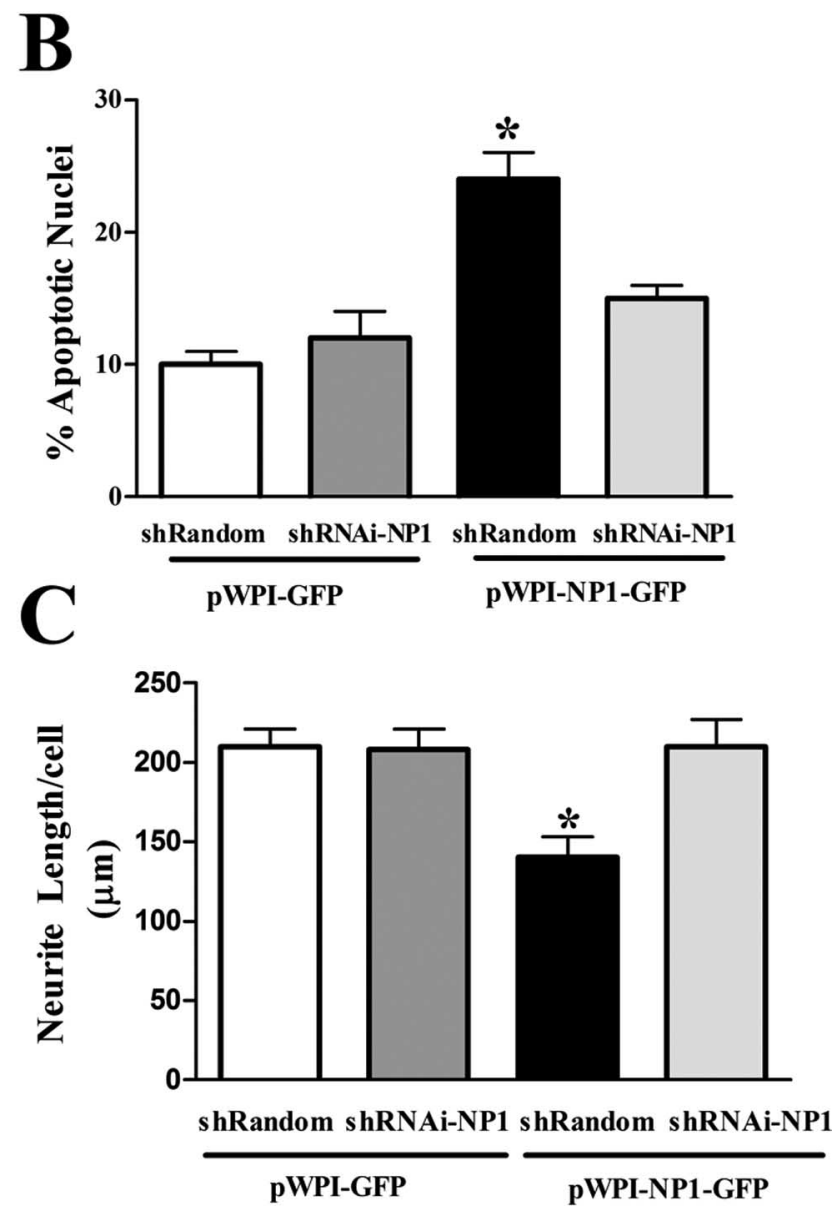

Figure 6. Transgene overexpression of NP1 increases apoptotic nuclei and reduces neurite outgrowth in cortical neuronal cultures. Cortical cells were treated with the bicistronic lentiviral vector for transgene expression of NP1 (pWPI-NP1) or with the control vector expressing GFP (pWPI-GFP). Silencing transgene expression of NP1 was performed with lentiviral-mediated RNAi. $\boldsymbol{A}$, Representative Western blot showing that transduction of cortical neurons with the lentivirus vector carrying the NP1 transgene increases the levels of NP1 in protein extracts and that silencing NP1 expression by RNAi with pLVTHM-shRNAi-NP1 is capable of reducing NP1 transgene overexpression. Actin was used as control for protein loading. Neurons were transduced at the time of plating, and protein extracts were obtained at 6 DIV. Western blots were incubated with mouse anti-NP1 antibody (1:1000). $\boldsymbol{B}$, Cortical neurons were transduced with the corresponding lentiviral vectors at the time of plating, and apoptotic nuclei were measured with Hoechst 33258 staining at 6 DIV. C, Cultures were transduced with the corresponding vectors, and total neurite length was estimated using a stereological procedure from phasecontrast photomicrographs obtained from living cells at 4 DIV. Values in $B$ and $C$ are mean \pm SE of at least three independent experiments. ${ }^{*} p<0.05$, significantly different from control values (one-way ANOVA with Bonferroni post hoc comparisons).
( $8 \pm 1 \%$ in controls compared with $23 \pm 4 \%$ in neurons transduced with NP1) (Fig. 6B). Both of these effects were blocked by silencing the expression of NP1 with the shRNAi-NP1 viral vector.

NP1 analysis on Western blots of human brain homogenates The antibody against NP1 used recognized a single band of $\sim 54$ $\mathrm{kDa}$ in homogenates of control and diseased human brain tissue. The intensity of the protein band recognized by this antibody was markedly augmented in tissue from AD cases. The specificity of this antibody for NP1 was confirmed by the fact that it failed to recognize this protein after preabsorption with recombinant GST-NP1 protein (Fig. 7A).

\section{Localization of NP1 immunoreactivity in control and}

\section{AD brains}

We analyzed the distribution of NP1 in the brain by immunohistochemistry and found that NP1 immunoreactivity in the hippocampus and entorhinal cortex of control tissue was restricted to the neuropil. The internal plexiform layer of the CA3 area of the hippocampus and the hilus of the dentate gyrus were particularly enriched in punctate NP1-immunoreactive deposits. Preabsorption of the antibody with the recombinant GST-NP1 protein completely abolished this staining (data not shown). NP1 immunoreactivity in $\mathrm{AD}$ tissue decorated the neuritic component of senile plaques while the amyloid core remained negative (Fig. $7 B, C$ ). This immunoreactivity was specific because no staining was observed when the sections were incubated with the preabsorbed antibody (Fig. 7D). When dual immunohistochemistry for NP1 and phospho-tau (AT8 antibody) was performed, it was evident that NP1 colocalized with tau deposits of dystrophic neurites in neuritic plaques (Fig. $7 E, F$ ). Furthermore, neurons with neurofibrillary tangles were not recognized by the anti-NP1 antibody, and therefore the increase in NP1 immunoreactivity in the soma of individual neurons was not associated with intracytoplasmic phosphorylated tau deposition (Fig. 7E,F). Doublelabeling immunofluorescence and confocal microscopy confirmed that expression of NP1 is localized around $\mathrm{A} \beta$ deposits in senile plaques in $\mathrm{AD}$ (Fig. $7 G$ ).

Moreover, mutant amyloid precursor protein/presenilin 1 (APP/PS1) transgenic mice displayed large numbers of $\mathrm{A} \beta$ plaques in the cerebral cortex and hippocampus (Fig. $7 H$ ). Consecutive sections stained with anti-phospho-tau antibodies demonstrated the presence of small phospho-tau-immunoreactive deposits surrounding A $\beta$ plaques (Fig. $7 I, J$ ). Antibodies to NP1 disclosed a similar punctate pattern in association with $\mathrm{A} \beta$ deposition.

Previous studies have shown that the synaptic protein SNAP-25 is highly expressed in dystrophic neurites in AD (Ferrer et al., 1998). To verify further the localization of NP1 in dysthophic neurites and its relationship with synaptic structures, we performed double-labeling immunofluorescence and confocal microscopy analysis of NP1 and SNAP-25 in AD brains. The results show that NP1 and SNAP-25 colocalize in the majority of dystrophic neurites surrounding amyloid deposits in senile plaques (Fig. 8).

\section{Discussion}

There are distinct lines of evidence indicating that the accumulation of $\mathrm{A} \beta$, and particularly of diffusible $\mathrm{A} \beta 1-42$, is responsible for progressive neurodegeneration in $\mathrm{AD}$. The characteristic sequence of events associated with this neurodegeneration commences with the early loss of synaptic contacts associated with the 
initiation of cognitive decline, and this is followed by neurite damage, neuronal shrinkage, and, finally, selective neuronal loss (Klein, 2002; Walsh and Selkoe, 2004). However, the molecular mechanisms that mediate these neurotoxic effects of $\mathrm{A} \beta$ remain to be characterized. Here, we report a novel mechanism that mediates $\mathrm{A} \beta$ neurotoxicity, which involves the overexpression of NP1, a protein implicated in synapse formation and remodeling (Schlimgen et al., 1995; Xu et al., 2003) that, at the same time, has been associated with the apoptotic program of cell death triggered by reduction in neuronal activity in mature cerebellar granule neurons (DeGregorio-Rocasolano et al., 2001; Enguita et al., 2005). Our experiments show that upregulation of NP1 expression contributes to synapse loss, neurite damage, and the subsequent apoptotic toxicity evoked by $\mathrm{A} \beta$ in cortical neuronal cultures. Indeed, treatment with oligomeric A $\beta 1-42$ decreases synaptophysin levels, reduces neurite outgrowth, and increases the expression of NP1 before markers of neuronal apoptosis can be detected (e.g., pyknotic nuclei and the cleavage of caspase 3). Moreover, silencing the overexpression of NP1 with RNAi prevents both the synaptic damage and the neuronal apoptosis evoked by $\mathrm{A} \beta$. In addition, our results show that there is a marked increase in NP1 protein levels in brain tissue from patients with late-onset $\mathrm{AD}$. The finding that this increase in NP1 immunoreactivity is associated with dystrophic neurites in brain tissue with $\mathrm{AD}$ as well as in a transgenic animal model of AD provides additional neuropathological evidence in support of the hypothesis that NP1 plays a key role in the neurodegeneration characteristic of $\mathrm{AD}$.

Soluble assemblies of synthetic A $\beta 1-42$ have been shown to be potent neurotoxins for different types of cell lines and organotypic cultures (Roher et al., 1996; Lambert et al., 1998; Hartley et al., 1999; Dahlgren et al., 2002). We have confirmed that synthetic oligomeric $A \beta 1-42$ does indeed induce a time- and concentration-dependent reduction in neuronal viability in primary cultures of cortical neurons. In accordance with previous studies, oligomeric $A \beta 1-42$ is a potent neurotoxin in culture, and a significant increase in apoptosis was observed at an effective concentration of $100 \mathrm{~nm}$. This neurotoxicity was not observed until $48 \mathrm{~h}$ after the beginning of treatment, and when the time course of higher concentrations was analyzed, the viability of cortical cells appeared to be unaffected during the first 18-24 h of treatment. Nevertheless, $A \beta$ induces a marked increase (twofold to threefold) in the levels of the NP1 protein within this period. Indeed, the increase in NP1 occurs well before the appearance of any
NP1
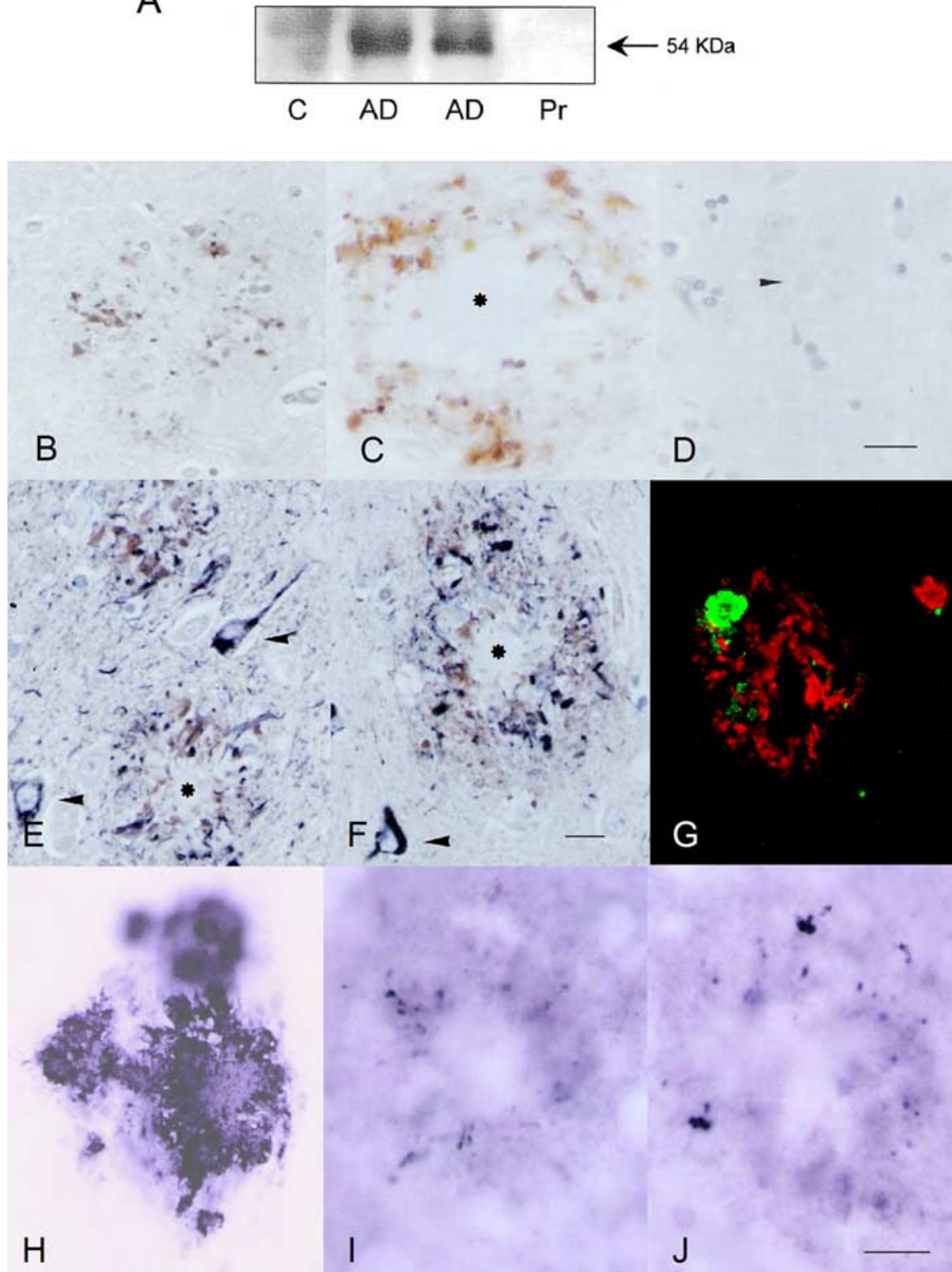

Figure 7. NP1 is expressed in abnormal neurites surrounding amyloid deposits of senile plaques in $A D$ and transgenic mice. $\boldsymbol{A}$, Western blots of hippocampal homogenates from control (C) and $A D$ tissue showing a band of $\sim 54 \mathrm{kDa}$, which is markedly increased in diseased brains. This band disappears after preabsorption (Pr) with the recombinant GST-NP1 protein. B, C, NP1 immunoreactivity is found in cellular processes surrounding amyloid cores (asterisk) in AD tissue. $\boldsymbol{D}$, NP1 immunoreactivity is abolished after incubation of the primary antibody with the recombinant GST-NP1 protein. $\boldsymbol{E}, \boldsymbol{F}$, Dual immunohistochemistry for NP1 (brown precipitate) and phospho-tau (AT8; dark blue precipitate) shows colocalization of NP1 and tau in dystrophic neurites of senile plaques, but not in neurons with neurofibrillary tangles (arrowheads). G, NP1 (green) and amyloid (red) immunofluorescence and confocal microscopy of a senile plaque. NP1 is in close vicinity of amyloid deposits in a senile plaque. NP1 immunoreactivity is also observed in APP/PS1 transgenic mice. $\boldsymbol{H}$, Cortical amyloid deposits in APP/PS1 transgenic mice. $\boldsymbol{I}$, Increased phospho-tau immunoreactivity (anti-tau phospho-specific $\mathrm{Thr}^{181}{ }^{18}$ ) in abnormal neurites surrounding amyloid cores. J, NP1 immunoreactivity has a similar localization, associated with amyloid cores in APP/PS1 transgenic mice. Cryostat sections with no counterstaining are shown. Scale bars: (in $\boldsymbol{D}) \boldsymbol{B}-\boldsymbol{D}$, (in $\boldsymbol{J}) \boldsymbol{H}-\boldsymbol{J}, 25 \mu \mathrm{m}$; (in $\boldsymbol{F}$ ) $\boldsymbol{E}, \boldsymbol{F}, 50 \mu \mathrm{m}$.

morphological or biochemical sign of apoptosis, indicating that the regulation of NP1 expression is an early event in the neurotoxic cascade activated by A $\beta$. Silencing NP1 expression with either antisense ODNs or RNAi prevents the synaptic damage and the appearance of morphological and biochemical signs of apoptosis evoked by $\mathrm{A} \beta$. Together with the observation that transgene overexpression of NP1 reproduces these neurotoxic 

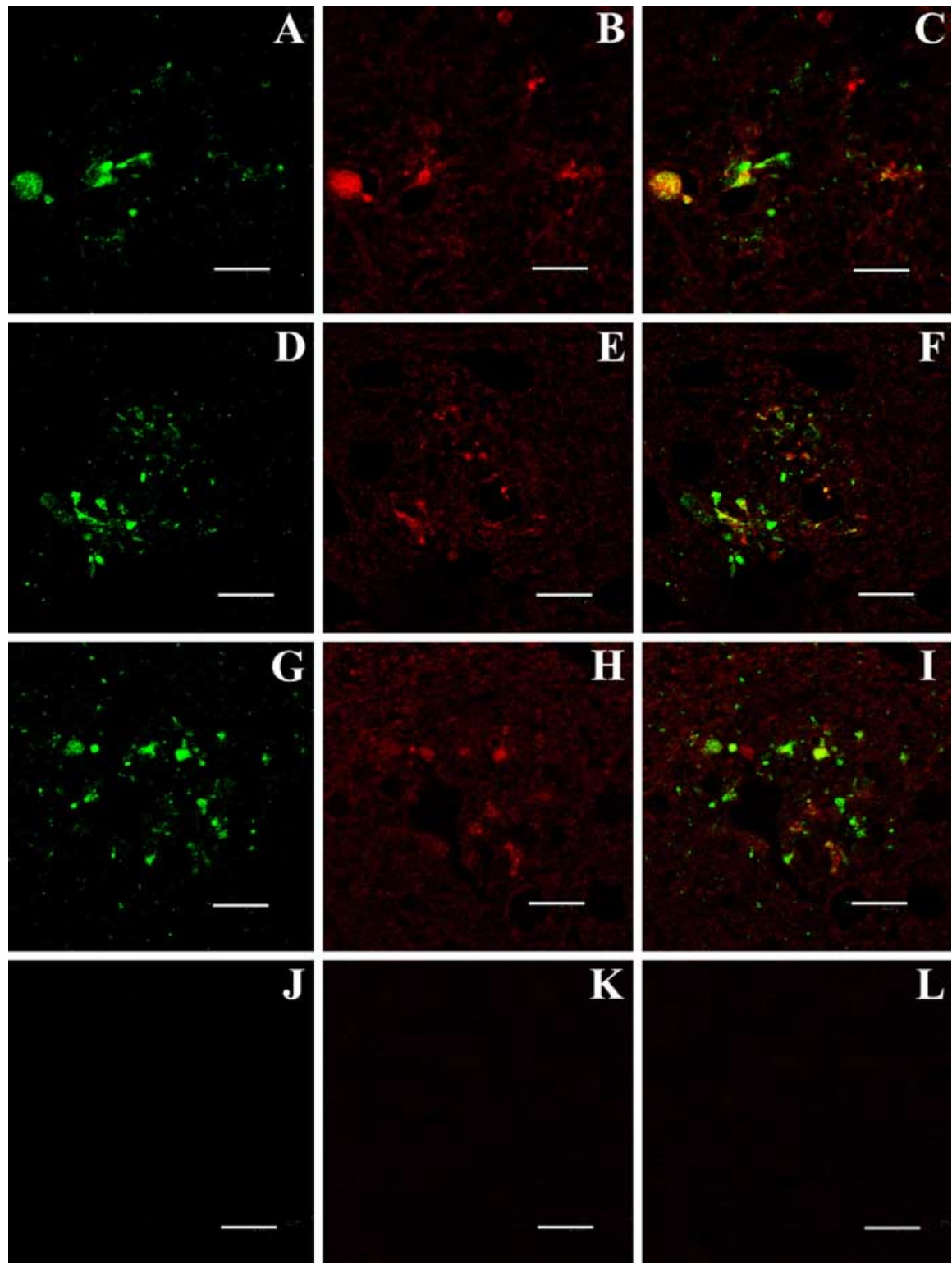

Figure 8. NP1 colocalizes with SNAP-25 in dystrophic neurites surrounding amyloid deposits. $\boldsymbol{A}-\boldsymbol{I}$, Double-labeling immunofluorescence to NP1 (green) and SNAP-25 (red) in three different senile plaques shows colocalization (merge, yellow) in the majority of abnormal neurites in human AD brains. $\boldsymbol{J}-\boldsymbol{L}$, Controls without the primary antibodies. Scale bars: A-C, $8 \mu \mathrm{m} ; \mathbf{D}-\boldsymbol{L}, 16 \mu \mathrm{m}$.

effects of $\mathrm{A} \beta$, we present robust evidence that the regulation of NP1 expression contributes to A $\beta$ neurotoxicity.

The relationship between NP1 and other factors known to contribute to $\mathrm{A} \beta$ neurotoxicity is presently unknown. Moreover, despite intense research, it remains unclear how $A \beta$ interacts with neurons and triggers the biochemical signaling cascade that leads to neuronal dysfunction and neurotoxicity. The present results indicate that regulation of NP1 expression is part of this neurotoxic signaling cascade. We have previously shown that overexpression of NP1 contributes to cerebellar granule cell death evoked by reduction in neuronal activity (DeGregorioRocasolano et al., 2001; Enguita et al., 2005). On the other hand, recent studies suggest that accumulation of $\mathrm{A} \beta$ may produce an excessive depression of excitatory synaptic transmission (Kamenetz et al., 2003). Therefore, we hypothesized that the signaling mechanisms activated by $\mathrm{A} \beta$ to produce neuronal dysfunction might be similar to those activated by the reduction in neuronal activity in cerebellar granule cells. The finding that NP1 expression is necessary for the neurotoxic effects of $A \beta$ is consistent

with this hypothesis. Thus, the present results suggest that the regulation of NP1 expression is part of a gene expressiondependent program of neurodegeneration activated by the accumulation of $\mathrm{A} \beta$ and that this shares mechanisms with the neuronal death process evoked by reduction in neuronal activity.

The intracellular signal transduction pathway through which $A \beta$ induces the gene expression-dependent program of neurodegeneration and the upregulation of NP1 has not been characterized, but several studies suggest that one of the steps of this pathway is modulation of glycogen synthase kinase 3 (GSK3) activity. Indeed, exposure of primary neuronal cultures to $\mathrm{A} \beta$ increases GSK3 activity (Takashima et al., 1998). Moreover, different laboratories have shown that inhibition of GSK3 activity blocks neurotoxicity evoked by $\mathrm{A} \beta$ (for review, see Bhat et al., 2004). Thus, $\mathrm{A} \beta$ induced neurotoxicity is reduced by antisense GSK3 oligonucleotides (Takashima et al., 1993), by the GSK3 inhibitor lithium (Alvarez et al., 1999; Wei et al., 2000), and by the more specific GSK3 inhibitor ARA014418 (Bhat et al., 2003). Furthermore, conditional overexpression of GSK3 in mice recapitulates different aspects of $\mathrm{AD}$ neuropathology (Engel et al., 2006). On the other hand, our previous studies indicate that GSK3 activity regulates NP1 expression. Thus, pharmacological reduction in GSK3 activity either with lithium or with the more specific GSK3 inhibitor SB415286 blocks NP1 overexpression and protects cerebellar granule neurons against death evoked by reduction in neuronal activity (DeGregorio-Rocasolano et al., 2001; Enguita et al., 2005). Therefore, it is possible that $\mathrm{A} \beta$ induces overexpression of NP1 by increasing GSK3 activity.

Evidence from different laboratories indicates that neuronal pentraxins may have several functions. Neuronal pentraxins were first proposed to participate in synapse formation and remodeling (Kirkpatrick et al., 2000; Schlimgen et al., 1995). In addition, NP1 and NP2 have been reported to mediate the synaptic clustering of AMPA glutamate receptors at a subset of excitatory synapses (Xu et al., 2003). Furthermore, the present results showing that overexpression of NP1 increases the percentage of neurons with apoptotic nuclei and cleaved caspase 3 provide additional evidence in support of the hypothesis that NP1 is part of the intrinsic program of apoptotic neuronal death activated by pathological stimuli in mature neurons. Nonetheless, which is the relationship among all of these different functions of NP1 and its role in the neuronal death program remains to be established. Mice that lack NP1 are viable, fertile, and show no obvious alteration in cerebral, cerebellar, hippocampal ultrastructure, or ob- 
vious changes of gait or behavior (Kirkpatrick et al., 2000). Functional redundancy with other pentraxins or with other compensatory mechanisms during neuronal development may explain the absence of a clear phenotype in NP1 knock-out mice. However, our results with RNAi of NP1 expression reported here predict that NP1 knock-out mice should show resistance to the neurotoxic effects of $A \beta$. NP1 needs to be induced by reduction in neuronal activity to exert its pro-apoptotic effect. Thus, we would not expect NP1 knock-out mice to have a lethal overabundance of neurons. Mutant mice that lack NP2 and NPR are also available (Kirkpatrick et al., 2000). In future experiments, it will be interesting to determine whether the lack of these other pentraxins prevents the neurotoxic effects of $\mathrm{A} \beta$ oligomers.

The neuropathological results in brains from patients with $\mathrm{AD}$ and APP/PS1 transgenic mice reported here emphasize that the restriction of NP1 to the neuropil in control hippocampal and entorhinal cortical tissue is consistent with the synaptic localization of NP1. Moreover, the observation that dystrophic neurites but not the amyloid core of AD brains exhibit high NP1 immunoreactivity is additional evidence that $\mathrm{A} \beta$ overproduction triggers a process of neuronal damage similar to that observed in cerebellar granule cells after deafferentiation. In support of the notion that NP1 immunoreactivity is associated with $\mathrm{A} \beta$ neurotoxicity, dual immunohistochemistry for NP1 and tau highlighted the colocalization of NP1 with tau deposits in dystrophic neurites in neuritic plaques. Similar observations regarding abnormal neurites containing NP1 in association with A $\beta$ plaques were also found in APP/PS1 transgenic mice. The localization of NP1 and abnormal cell processes in AD brains were also supported by double-labeling immunofluorescence and confocal microscopy studies showing that NP1 colocalizes with the synaptosomal-associated protein SNAP-25 in the majority of dystrophic neurites surrounding amyloid deposits in senile plaques. SNAP-25 has previously been reported to be reduced in the amyloid core but highly expressed in abnormal neurites surrounding amyloid deposits in AD (Ferrer et al., 1998).

High levels of $A \beta$ selectively depress excitatory synaptic transmission in neurons that overexpress APP, as well as in nearby neurons that do not (Kamenetz et al., 2003). This phenomenon also suggests that $\mathrm{A} \beta$ activates a signal transduction pathway that, similarly to what occurs after reduction in neuronal activity, triggers the apoptotic program of neurodegeneration. The finding that silencing the expression of NP1 prevents the decrease in synaptophysin levels evoked by A $\beta$ suggests that NP1 contributes to the synaptic damage evoked by $\mathrm{A} \beta$ and provides a molecular basis for this $\mathrm{A} \beta$-induced depression of synaptic transmission. The interpretation that NP1 regulates synaptogenesis and synaptophysin levels in response to changes in neuronal activity is supported by recent studies showing that NP1 knock-out mice exhibit defects in the segregation of eye-specific retinal ganglion cell projections to the dorsal lateral geniculate nucleus, a process that involves activity-dependent synapse formation (Bjartmar et al., 2006). Moreover, NP1 has been proposed to regulate synaptogenesis by forming pentraxin heterocomplexes with NP2 (Xu et al., 2003). Expression of NP2 is responsive to activity, and it is rapidly upregulated by intense neuronal activation such as maximal electroconvulsive seizure (Xu et al., 2003). On the contrary, NP1 expression is rapidly increased by reduction in neuronal activity and causes cell death (DeGregorio-Rocasolano et al., 2001; Enguita et al., 2005). Based on these observations, we propose that neuronal pentraxins might constitute a genetic switch that regulates neuronal death or survival depending on synaptic activity (DeGregorio-Rocasolano et al., 2001).
The observation that RNAi of NP1 expression prevents both the decrease in synaptophysin levels and the reduction in neurite outgrowth evoked by $\mathrm{A} \beta$, together with the finding that NP1 is increased in dystrophic neurites in brains from AD patients, indicates that NP1 plays a key role in the synaptic degeneration that occurs in the early stages of AD. The mechanism by which NP1 modulates synaptophysin levels and neurite outgrowth is still unknown. Recently, it has been reported that the NPR with chromo domain (NPCD) interacts with the cytoplasmic catalytic phosphatase domain of the receptor protein tyrosine phosphatase PTPRO and that such interaction is required for NGFinduced neurite outgrowth (Chen and Bixby, 2005b). We speculate that the decrease in neurite outgrowth observed after overexpression of NP1 could be produced through an interaction of NP1 with the NPCD receptor that would subsequently alter the phosphatase activity of PTPRO required for neurite outgrowth. This hypothesis is currently under investigation.

In summary, we have shown that upregulation of NP1 expression plays a key role in the synaptic loss, neurite damage, and apoptotic neurotoxicity evoked by A $\beta$ oligomers. These results, together with the finding that NP1 is increased in dystrophic neurites in brains with AD and in APP/PS1 transgenic mice, suggest that $\mathrm{A} \beta$ contributes to the pathology of $\mathrm{AD}$ by regulating NP1 expression. Future studies will determine the extent of the contribution of NP1 to the cognitive decline characteristic of AD.

\section{References}

Alvarez G, Munoz-Montano JR, Satrustegui J, Avila J, Bogonez E, Diaz-Nido J (1999) Lithium protects cultured neurons against beta-amyloidinduced neurodegeneration. FEBS Lett 453:260-264.

Bhat R, Xue Y, Berg S, Hellberg S, Ormo M, Nilsson Y, Radesater AC, Jerning E, Markgren PO, Borgegard T, Nylof M, Gimenez-Cassina A, Hernandez F, Lucas JJ, Diaz-Nido J, Avila J (2003) Structural insights and biological effects of glycogen synthase kinase 3-specific inhibitor AR-A014418. J Biol Chem 278:45937-45945.

Bhat RV, Budd Haeberlein SL, Avila J (2004) Glycogen synthase kinase 3: a drug target for CNS therapies. J Neurochem 89:1313-1317.

Bjartmar L, Huberman AD, Ullian EM, Renteria RC, Liu X, Xu W, Prezioso J, Susman MW, Stellwagen D, Stokes CC, Cho R, Worley P, Malenka RC, Ball S, Peachey NS, Copenhagen D, Chapman B, Nakamoto M, Barres BA, Perin MS (2006) Neuronal pentraxins mediate synaptic refinement in the developing visual system. J Neurosci 26:6269-6281.

Braak H, Braak E (2001) Temporal sequence of Alzheimer's disease-related pathology. In: Cerebral cortex. Neurodegenerative and age-related changes in structure and function of cerebral cortex (Peters A, Morrison JH, eds), pp 475-512. New York: Kluwer Academic/Plenum.

Chen B, Bixby JL (2005a) A novel substrate of receptor tyrosine phosphatase PTPRO is required for nerve growth factor-induced process outgrowth. J Neurosci 25:880-888.

Chen B, Bixby JL (2005b) Neuronal pentraxin with chromo domain (NPCD) is a novel class of protein expressed in multiple neuronal domains. J Comp Neurol 481:391-402.

Dahlgren KN, Manelli AM, Stine Jr WB, Baker LK, Krafft GA, LaDu MJ (2002) Oligomeric and fibrillar species of amyloid-beta peptides differentially affect neuronal viability. J Biol Chem 277:32046-32053.

Davies CA, Mann DM, Sumpter PQ, Yates PO (1987) A quantitative morphometric analysis of the neuronal and synaptic content of the frontal and temporal cortex in patients with Alzheimer's disease. J Neurol Sci 78:151-164.

DeGregorio-Rocasolano N, Gasull T, Trullas R (2001) Overexpression of neuronal pentraxin 1 is involved in neuronal death evoked by low $\mathrm{K}+$ in cerebellar granule cells. J Biol Chem 276:796-803.

DeKosky ST, Scheff SW (1990) Synapse loss in frontal cortex biopsies in Alzheimer's disease: correlation with cognitive severity. Ann Neurol 27:457-464.

D'mello SR, Galli C, Ciotti T, Calissano P (1993) Induction of apoptosis in cerebellar granule neurons by low potassium-inhibition of death by insulin-like growth factor-I and cAMP. Proc Natl Acad Sci USA 90:10989-10993. 
Dodds DC, Omeis IA, Cushman SJ, Helms JA, Perin MS (1997) Neuronal pentraxin receptor, a novel putative integral membrane pentraxin that interacts with neuronal pentraxin 1 and 2 and taipoxin-associated calcium-binding protein 49. J Biol Chem 272:21488-21494.

Elbashir SM, Lendeckel W, Tuschl T (2001) RNA interference is mediated by 21- and 22- nucleotide RNAs. Genes Dev 15:188-200.

Engel T, Hernandez F, Avila J, Lucas JJ (2006) Full reversal of Alzheimer's disease-like phenotype in a mouse model with conditional overexpression of glycogen synthase kinase-3. J Neurosci 26:5083-5090.

Enguita M, DeGregorio-Rocasolano N, Abad A, Trullas R (2005) Glycogen synthase kinase 3 activity mediates neuronal pentraxin 1 expression and cell death induced by potassium deprivation in cerebellar granule cells. Mol Pharmacol 67:1237-1246.

Estus S, Tucker HM, van Rooyen C, Wright S, Brigham EF, Wogulis M, Rydel RE (1997) Aggregated amyloid- $\beta$ protein induces cortical neuronal apoptosis and concomitant "apoptotic" pattern of gene induction. J Neurosci $17: 7736-7745$

Ferrer I, Marti E, Tortosa A, Blasi J (1998) Dystrophic neurites of senile plaques are defective in proteins involved in exocytosis and neurotransmission. J Neuropathol Exp Neurol 57:218-225.

Hartley DM, Walsh DM, Ye CP, Diehl T, Vasquez S, Vassilev PM, Teplow DB, Selkoe DJ (1999) Protofibrillar intermediates of amyloid $\beta$-protein induce acute electrophysiological changes and progressive neurotoxicity in cortical neurons. J Neurosci 19:8876-8884.

Hsu YC, Perin MS (1995) Human neuronal pentraxin II (NPTX2): conservation, genomic structure, and chromosomal localization. Genomics 28:220-227.

Ivins KJ, Bui ET, Cotman CW (1998) Beta-amyloid induces local neurite degeneration in cultured hippocampal neurons: evidence for neuritic apoptosis. Neurobiol Dis 5:365-378.

Kamenetz F, Tomita T, Hsieh H, Seabrook G, Borchelt D, Iwatsubo T, Sisodia S, Malinow R (2003) APP processing and synaptic function. Neuron 37:925-937.

Kirkpatrick LL, Matzuk MM, Dodds DC, Perin MS (2000) Biochemical interactions of the neuronal pentraxins. J Biol Chem 275:17786-17792.

Klein WL (2002) Abeta toxicity in Alzheimer's disease: globular oligomers (ADDLs) as new vaccine and drug targets. Neurochem Int 41:345-352.

Lambert MP, Barlow AK, Chromy BA, Edwards C, Freed R, Liosatos M, Morgan TE, Rozovsky I, Trommer B, Viola KL, Wals P, Zhang C, Finch CE, Krafft GA, Klein WL (1998) Diffusible, nonfibrillar ligands derived from Abeta1-42 are potent central nervous system neurotoxins. Proc Natl Acad Sci USA 95:6448-6453.

Loo DT, Copani A, Pike CJ, Whittemore ER, Walencewicz AJ, Cotman CW (1993) Apoptosis is induced by beta-amyloid in cultured central nervous system neurons. Proc Natl Acad Sci USA 90:7951-7955.

Masliah E, Mallory M, Alford M, Deteresa R, Hansen LA, McKeel Jr DW, Morris JC (2001) Altered expression of synaptic proteins occurs early during progression of Alzheimer's disease. Neurology 56:127-129.

Morishima Y, Gotoh Y, Zieg J, Barrett T, Takano H, Flavell R, Davis RJ, Shirasaki Y, Greenberg ME (2001) $\beta$-Amyloid induces neuronal apoptosis via a mechanism that involves the c-Jun N-terminal kinase pathway and the induction of Fas ligand. J Neurosci 21:7551-7560.

O’Brien RJ, Xu D, Petralia RS, Steward O, Huganir RL, Worley P (1999) Synaptic clustering of AMPA receptors by the extracellular immediateearly gene product Narp. Neuron 23:309-323.

Osmand AP, Friedenson B, Gewurz H, Painter RH, Hofmann T, Shelton E (1977) Characterization of C-reactive protein and the complement subcomponent $\mathrm{C} 1 \mathrm{t}$ as homologous proteins displaying cyclic pentameric symmetry (pentraxins). Proc Natl Acad Sci USA 74:739-743.

Pike CJ, Walencewicz-Wasserman AJ, Kosmoski J, Cribbs DH, Glabe CG,
Cotman CW (1995) Structure-activity analyses of beta-amyloid peptides: contributions of the beta 25-35 region to aggregation and neurotoxicity. J Neurochem 64:253-265.

Roher AE, Chaney MO, Kuo YM, Webster SD, Stine WB, Haverkamp LJ Woods AS, Cotter RJ, Tuohy JM, Krafft GA, Bonnell BS, Emmerling MR (1996) Morphology and toxicity of Abeta-(1-42) dimer derived from neuritic and vascular amyloid deposits of Alzheimer's disease. J Biol Chem 271:20631-20635.

Ronn LC, Ralets I, Hartz BP, Bech M, Berezin A, Berezin V, Moller A, Bock E (2000) A simple procedure for quantification of neurite outgrowth based on stereological principles. J Neurosci Methods 100:25-32.

Rudolph JG, Lemasters JJ, Crews FT (1997) Use of a multiwell fluorescence scanner with propidium iodide to assess NMDA mediated excitotoxicity in rat cortical neuronal cultures. Neurosci Lett 221:149-152.

Schlimgen AK, Helms JA, Vogel H, Perin MS (1995) Neuronal pentraxin, a secreted protein with homology to acute phase proteins of the immune system. Neuron 14:519-526.

Selkoe DJ (2002) Alzheimer's disease is a synaptic failure. Science 298:789-791.

Takahashi RH, Almeida CG, Kearney PF, Yu F, Lin MT, Milner TA, Gouras GK (2004) Oligomerization of Alzheimer's $\beta$-amyloid within processes and synapses of cultured neurons and brain. J Neurosci 24:3592-3599.

Takashima A, Noguchi K, Sato K, Hoshino T, Imahori K (1993) Tau protein kinase I is essential for amyloid beta-protein-induced neurotoxicity. Proc Natl Acad Sci USA 90:7789-7793.

Takashima A, Honda T, Yasutake K, Michel G, Murayama O, Murayama M Ishiguro K, Yamaguchi H (1998) Activation of tau protein kinase I/glycogen synthase kinase-3beta by amyloid beta peptide (25-35) enhances phosphorylation of tau in hippocampal neurons. Neurosci Res 31:317-323.

Tsui CC, Copeland NG, Gilbert DJ, Jenkins NA, Barnes C, Worley PF (1996) Narp, a novel member of the pentraxin family, promotes neurite outgrowth and is dynamically regulated by neuronal activity. J Neurosci 16:2463-2478.

Walsh DM, Selkoe DJ (2004) Deciphering the molecular basis of memory failure in Alzheimer's disease. Neuron 44:181-193.

Wei H, Leeds PR, Qian Y, Wei W, Chen R, Chuang D (2000) beta-amyloid peptide-induced death of PC12 cells and cerebellar granule cell neurons is inhibited by long-term lithium treatment. Eur J Pharmacol 392:117-123.

Wei W, Wang X, Kusiak JW (2002) Signaling events in amyloid betapeptide-induced neuronal death and insulin-like growth factor I protection. J Biol Chem 277:17649-17656.

Whitehouse PJ, Price DL, Struble RG, Clark AW, Coyle JT, DeLong MR (1982) Alzheimer's disease and senile dementia; loss of neurons in the basal forebrain. Science 215:1237-1239.

Wiznerowicz M, Trono D (2003) Conditional suppression of cellular genes: lentivirus vector-mediated drug-inducible RNA interference. J Virol 77:8957-8961.

Wiznerowicz M, Trono D (2005) Harnessing HIV for therapy, basic research and biotechnology. Trends Biotechnol 23:42-47.

Xu D, Hopf C, Reddy R, Cho RW, Guo L, Lanahan A, Petralia RS, Wenthold RJ, O'Brien RJ, Worley P (2003) Narp and NP1 form heterocomplexes that function in developmental and activity-dependent synaptic plasticity. Neuron 39:513-528.

Yankner BA, Duffy LK, Kirschner DA (1990) Neurotrophic and neurotoxic effects of amyloid beta protein: reversal by tachykinin neuropeptides. Science 250:279-282.

Zufferey R, Dull T, Mandel RJ, Bukovsky A, Quiroz D, Naldini L, Trono D (1998) Self-inactivating lentivirus vector for safe and efficient in vivo gene delivery. J Virol 72:9873-9880. 